\title{
Boundary Layer Convergence Induced by Strong Winds across a Midlatitude SST Front*
}

\author{
Thomas Kilpatrick, Niklas SchneIDER, AND Bo QIU \\ Department of Oceanography, and International Pacific Research Center, University of Hawai' $i$ at Mānoa, \\ Honolulu, Hawaii
}

(Manuscript received 11 February 2013, in final form 30 October 2013)

\begin{abstract}
Recent studies indicate that the influence of midlatitude SST fronts extends through the marine atmospheric boundary layer (MABL) into the free atmosphere, with implications for climate variability. To better understand the mechanisms of this ocean-to-atmosphere influence, SST-induced MABL convergence is explored here with the Weather Research and Forecasting mesoscale model in an idealized, dry, twodimensional configuration, for winds crossing from cold to warm SST and from warm to cold SST.

For strong cross-front winds, $O\left(10 \mathrm{~m} \mathrm{~s}^{-1}\right)$, changes in the turbulent mixing and MABL depth across the SST front lead to MABL depth-integrated convergence in the cold-to-warm case and depth-integrated divergence in the warm-to-cold case. The turbulent stress divergence term changes over a shorter length scale than the pressure gradient and Coriolis terms, such that the MABL response directly above the SST front is governed by nonrotating, internal boundary layer-like physics, which are consistent with the vertical mixing mechanism. An important consequence is that the increment in the cross-front surface stress diagnoses the vertical motion at the top of the MABL. These physics are at variance with some previously proposed SST frontal MABL models in which pressure adjustments determine the MABL convergence.

The SST-induced MABL convergence results in vertical motion that excites a stationary internal gravity wave in the free atmosphere, analogous to a mountain wave. For a $15 \mathrm{~m} \mathrm{~s}^{-1}$ cross-front wind, the gravity wave forced by an SST increase of $3^{\circ} \mathrm{C}$ over $200 \mathrm{~km}$ is comparable to that forced by an $80-\mathrm{m}$ change in topography.
\end{abstract}

\section{Introduction}

The influence of SST fronts on surface winds, surface wind stress, and the marine atmospheric boundary layer (MABL) structure is now supported by in situ observations, global satellite scatterometer measurements, and modeling studies (see reviews in, e.g., Xie 2004; Chelton et al. 2004; Small et al. 2008; Chelton and Xie 2010). The scatterometer measurements show that on spatial scales of $50-500 \mathrm{~km}$, the surface wind stress magnitude and surface wind speed increase over warm SST and decrease over cool SST (Fig. 1). Likewise, the wind stress curl is

\footnotetext{
* International Pacific Research Center publication number 1034 and School of Ocean and Earth Science and Technology publication number 9055 .

Corresponding author address: Thomas Kilpatrick, Scripps Institution of Oceanography/UCSD, 9500 Gilman Dr., \#0206, La Jolla, CA 92093-0206.

E-mail: thomaski@hawaii.edu
}

sensitive to the crosswind SST gradient and the wind stress divergence is sensitive to the downwind SST gradient (Chelton et al. 2004; O'Neill et al. 2003, 2005; Chelton et al. 2007; Chelton and Xie 2010), as illustrated in Fig. 1 for a uniform synoptic-scale wind blowing over a meandering SST front: the wind stress curl is strong where the surface winds are oriented in the alongfront direction (red region) and the wind stress divergence is strong where the surface winds are oriented in the crossfront direction (blue region).

The two physical mechanisms typically cited for this oceanic influence on the MABL are the "vertical mixing mechanism" (Wallace et al. 1989; Hayes et al. 1989) and the "pressure adjustment mechanism" (Lindzen and Nigam 1987). According to the vertical mixing mechanism, a destabilizing air-sea heat flux over warm SST increases the turbulent mixing and deepens the MABL; momentum is mixed downward from aloft, increasing the surface wind speed and stress. According to the pressure adjustment mechanism, the air-sea heat flux imprints the underlying SST pattern in the MABL temperature, thus 


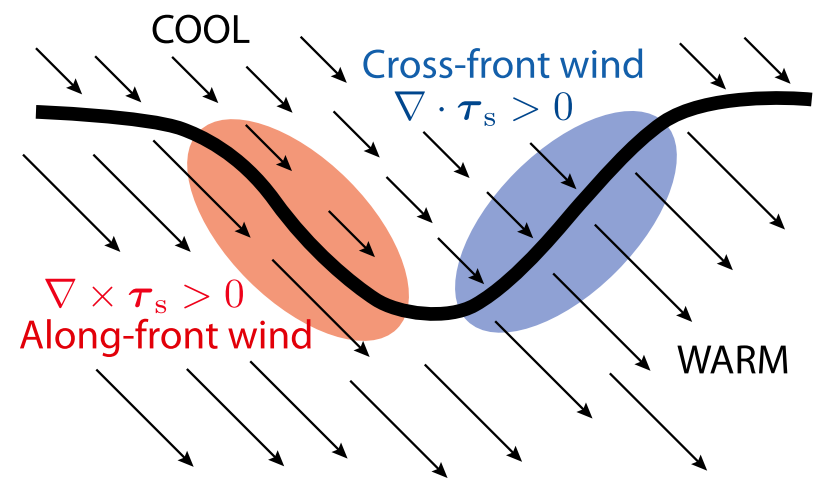

FIG. 1. Schematic of the surface wind stress (arrows) response to a meandering SST front (thick black curve represents SST isotherms), adapted from Chelton et al. (2004, their Fig. S6). Scatterometer measurements indicate that surface wind stress magnitude and surface wind speed increase over warm SST and decrease over cool SST. Likewise, strong wind stress curl is found in regions with alongfront surface winds (red area) and strong wind stress divergence is found in regions with cross-front surface winds (blue area).

creating hydrostatic pressure gradients in the MABL; these pressure gradients then act to accelerate the surface winds. Surface winds and stress show sensitivity to both the vertical mixing and pressure adjustment mechanisms depending on the background wind speed, SST frontal length scale, and latitude (Small et al. 2008).

Although the SST frontal influence on surface winds and stress is established, it is not clear how an SST front may affect the free atmosphere. Are the changes to the atmosphere evident in the wind stress fields (Fig. 1) confined to the MABL, or do they penetrate into the free atmosphere? Through what mechanisms may an SST front influence the free atmosphere?

The classical view is that the atmospheric boundary layer interacts with the synoptic-scale circulation through Ekman pumping and spindown (Charney and Eliassen 1949; Mahrt and Park 1976; Holton 2004; Beare 2007). Boundary layer convergence forces vertical motion that acts to "spin down" the synoptic-scale flow via vortex stretching. However, the Ekman model proposed by Feliks et al. (2004) for SST frontal zones acts to drive the largescale circulation in quasigeostrophic models (Feliks et al. 2004, 2007, 2011), a radical departure from the spindown concept. Minobe et al. (2008) propose a similar MABL model to Feliks et al. (2004) and argue that SST frontinduced MABL convergence is important for forcing the deep atmosphere above the Gulf Stream. However, Adamson et al. (2006) consider a developing midlatitude cyclone in the absence of SST fronts and find that Ekman pumping and spindown are not the primary mechanisms whereby boundary layer friction modifies the cyclone.

Regardless of the mechanism, the large-scale atmospheric circulation appears to be sensitive to the position of the Kuroshio and Oyashio fronts (Qiu et al. 2007; Frankignoul et al. 2011), while synoptic variability in the North Atlantic is sensitive to shifts in the Gulf Stream (Joyce et al. 2009). Many GCM studies have shown that storm tracks are sensitive to the presence and location of SST fronts (Nakamura et al. 2008; Nonaka et al. 2009; Taguchi et al. 2009; Sampe et al. 2010; Brayshaw et al. 2008, 2011). Therefore it seems timely to explore in more detail the MABL physics in the vicinity of an SST front, and how any SST front-induced changes may influence the free atmosphere.

Following Song et al. (2006) and especially Spall (2007, hereafter S07) we utilize a regional atmospheric model in a two-dimensional configuration to study the idealized problem of a vertically uniform geostrophic wind aligned in the cross-front direction (blue region in Fig. 1). The emphasis here is on the MABL depthintegrated convergence, resultant vertical motion, surface stress signal, and free atmosphere response. Section 2 discusses in more detail the SST frontal Ekman models mentioned above. Section 3 describes our regional atmospheric model configuration. An overview of the cold-to-warm and warm-to-cold cases is presented in section 4; the mechanisms of MABL convergence are considered in section 5; and the free atmosphere response is presented in section 6 . Section 7 closes with a summary and discussion.

\section{Models of MABL convergence for SST frontal zones}

An Ekman momentum balance is a three-way balance among the Coriolis, pressure gradient, and stress divergence terms:

$$
f \hat{\mathbf{k}} \times \mathbf{u}=-\frac{1}{\rho_{0}} \nabla p+\frac{1}{\rho_{0}} \frac{\partial \tau}{\partial z},
$$

where $f$ is the Coriolis parameter, $\hat{\mathbf{k}}$ is the vertical unit vector, $\mathbf{u}$ is the horizontal wind, $\rho_{0}$ is a reference air density, $\boldsymbol{\nabla}$ is the horizontal gradient operator, $p$ is the pressure, and $\tau$ is the stress.

The Ekman model proposed by Feliks et al. (2004) for SST frontal zones is exactly Eq. (1), with the stress given by $\tau / \rho_{0}=K \partial_{z} \mathbf{u}$, where $K$ is a constant eddy diffusivity and a no-slip surface boundary condition is used; the underlying SST pattern imprints a lateral temperature gradient into the Ekman layer via the air-sea heat flux (Lindzen and Nigam 1987), such that the pressure gradient $\nabla p$ is baroclinic. Feliks et al. (2004) derive an Ekman pumping velocity from Eq. (1) that contains two terms: the first term acts to damp the large-scale vorticity, as in traditional spindown (e.g., Holton 2004); the second term is a function of the Laplacian of the SST 
field and acts to drive the quasigeostrophic circulation aloft (Feliks et al. 2004, 2007, 2011).

Minobe et al. (2008) proposed a mixed-layer model of MABL convergence for SST frontal zones:

$$
f \hat{\mathbf{k}} \times \mathbf{u}=-\frac{1}{\rho_{0}} \nabla p-\alpha \mathbf{u},
$$

where $\alpha$ is a constant Rayleigh friction coefficient. The MABL temperature is in equilibrium with SST. The hydrostatic pressure gradient $\nabla p$ therefore reflects the underlying SST gradient, although $\nabla p$ in Eq. (2) is barotropic, in contrast to Feliks et al. (2004).

Manipulating the divergence and curl of Eq. (2) yields a relation between the boundary layer wind convergence and pressure Laplacian:

$$
-\left(\frac{\partial u}{\partial x}+\frac{\partial v}{\partial y}\right) \rho_{0}=\left(\frac{\alpha}{\alpha^{2}+f^{2}}\right) \nabla^{2} p .
$$

The mixed-layer model of Eqs. (2) and (3) is known as the pressure adjustment mechanism because of its resemblance to the MABL model of Lindzen and Nigam (1987).

Satellite observations and GCMs indicate a correspondence between surface wind convergence and sea level pressure (SLP) Laplacian in SST frontal zones, consistent with Eq. (3); this correspondence is often taken as implicit evidence for the mixed-layer physics of Eq. (2) (Minobe et al. 2008, 2010; Bryan et al. 2010; Kuwano-Yoshida et al. 2010; Shimada and Minobe 2011). However, we will show that the mixed-layer assumption breaks down for strong cross-front winds, as the surface wind convergence is the opposite sign of the MABL depth-integrated convergence (section 5e).

The MABL models proposed by Feliks et al. (2004) and Minobe et al. (2008) both represent an Ekman momentum balance. The MABL convergence in both models is determined by hydrostatic pressure adjustments. However, in section 5 we show that for strong cross-front winds, MABL convergence is primarily a function of lateral heterogeneity in turbulent mixing.

\section{Regional atmospheric model experiments}

The atmospheric response to an idealized midlatitude SST front is explored here with the nonhydrostatic Weather Research and Forecasting model (WRF), version 3.3.1 (Skamarock et al. 2008). WRF has been used to study ocean-to-atmosphere influence over the Agulhas Return Current (Song et al. 2009; O'Neill et al. 2010b) and the Kuroshio (Xu et al. 2010, 2011; Tanimoto et al. 2011).

A two-dimensional $(x-z)$ configuration is achieved with the normal three-dimensional WRF codes by using one row of grid points in the zonal (cross-front) direction and a periodic boundary condition in the meridional (alongfront) direction. A barotropic meridional pressure gradient $\partial_{y} \phi$ is imposed to balance a vertically uniform geostrophic zonal wind $\bar{U}$. Following $\mathrm{S} 07, \bar{U}$ is set to $\pm 15 \mathrm{~m} \mathrm{~s}^{-1}$ for the base cases $\left(\bar{U}=15 \mathrm{~m} \mathrm{~s}^{-1}\right.$ corresponds to wind speeds of $8.5-11 \mathrm{~m} \mathrm{~s}^{-1}$ at the lowest model level; Fig. 3), although a broader range of background wind speeds is considered in sections $5 \mathrm{c}$ and $5 \mathrm{f}$. The upwind and downwind boundaries use a radiation condition in the zonal direction, allowing gravity waves to propagate out of the domain as described in Klemp and Lilly (1978) and Klemp and Wilhelmson (1978).

The dimensions of the model domain are $3600 \mathrm{~km}$ in the zonal direction and $20 \mathrm{~km}$ in the vertical. The horizontal resolution is $6 \mathrm{~km}$. There are 86 grid points in the vertical, with 44 points concentrated in the bottom $2 \mathrm{~km}$. An $f$-plane geometry is used with $f=10^{-4} \mathrm{~s}^{-1}$. The buoyancy frequency is $N=0.01 \mathrm{~s}^{-1}$ in the troposphere (corresponding to a lapse rate of $6.8 \mathrm{~K} \mathrm{~km}^{-1}$ ) and $N=0.021 \mathrm{~s}^{-1}$ in the stratosphere, with the tropopause at $12 \mathrm{~km}$. SST is fixed to

$$
T(x)=15.8^{\circ} \mathrm{C}+\frac{\Delta T}{2} \tanh \left(\frac{x}{L_{T}}\right),
$$

with $\Delta T=3^{\circ} \mathrm{C}$ and $L_{T}=100 \mathrm{~km}$, so that the SST front is approximately $200 \mathrm{~km}$ wide and centered at $x=0 \mathrm{~km}$ (Fig. 2d, dashed line).

The primary focus of this study is the atmospheric response for "strong" cross-front winds, which are defined here as having an $O(1)$ cross-front Rossby number $\epsilon=U / f L$, where $U$ is the cross-front component of the MABL wind and $L$ is the length scale of the SST front. The base cases have strong cross-front winds because $U=O\left(10 \mathrm{~m} \mathrm{~s}^{-1}\right)$ and $L \approx 200 \mathrm{~km}$, such that $\epsilon=O(1)$.

The Nakanishi and Niino (2006) level 3 scheme is used for subgrid-scale turbulent mixing. This Mellor and Yamada (1982)-type scheme parameterizes turbulent vertical fluxes of momentum and potential temperature as

$$
\begin{aligned}
& \langle u w\rangle=-K_{M} \frac{\partial U}{\partial z}, \\
& \langle\theta w\rangle=-K_{H} \frac{\partial \Theta}{\partial z},
\end{aligned}
$$

where lower-case variables (lhs) denote unresolved turbulent quantities and upper-case variables (rhs) denote resolved quantities. The mixing coefficients $K_{M, H}$ are a function of a master length scale and the turbulent kinetic energy [see Nakanishi and Niino (2006) for details]. We refer to both $\tau$ and $\tau / \rho_{0}$ as the "stress," where

$$
\begin{aligned}
\tau / \rho_{0} & =\left(\tau_{x}, \tau_{y}\right) / \rho_{0} \\
& =-(\langle u w\rangle,\langle v w\rangle) .
\end{aligned}
$$

Hereafter, lower-case variables denote resolved model quantities. 

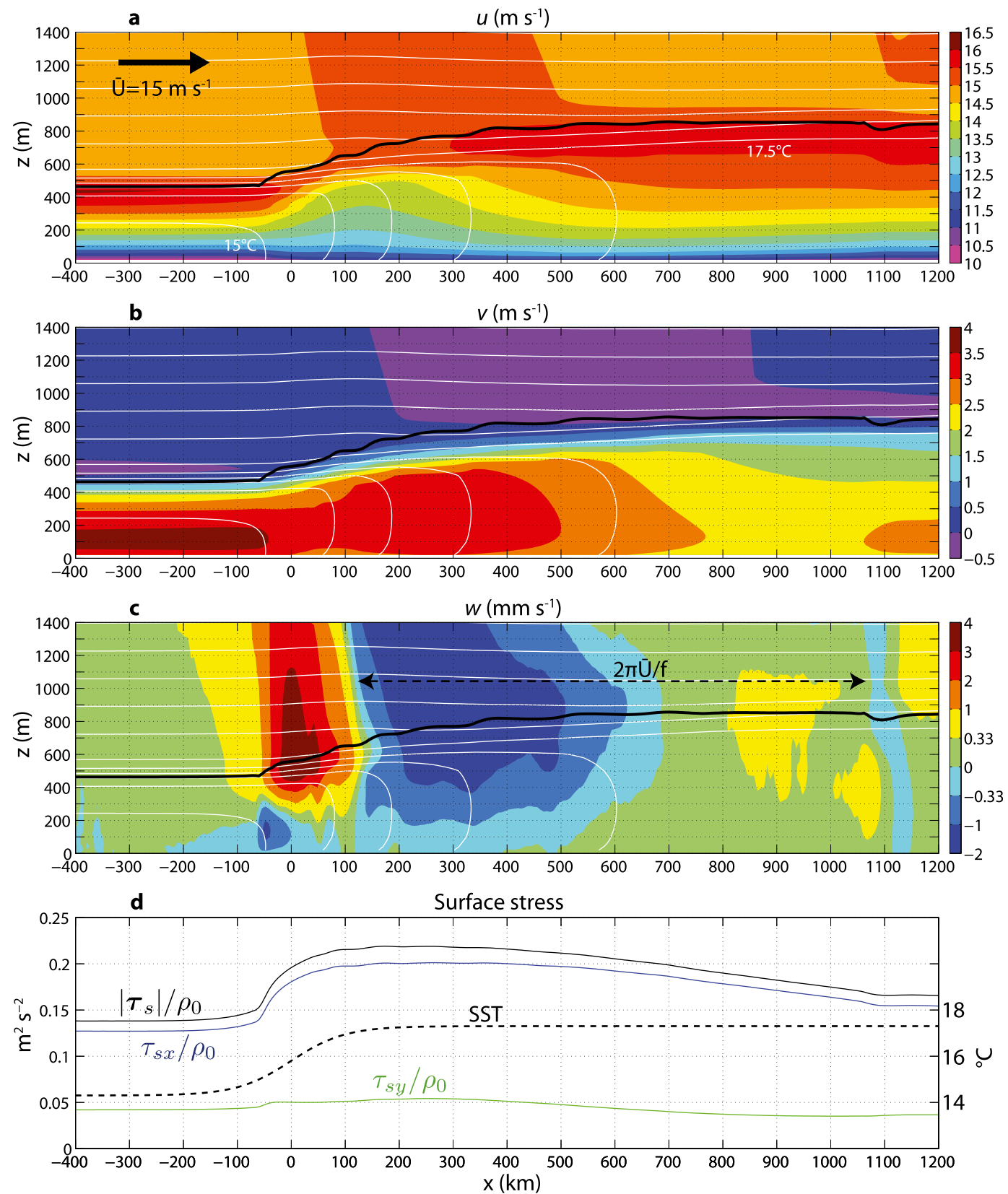

FIG. 2. Snapshots of model fields at $24 \mathrm{~h}$ for the cold-to-warm case $\left(\bar{U}=15 \mathrm{~m} \mathrm{~s}^{-1}\right)$ : (a) $u$ (color; $\mathrm{m} \mathrm{s}^{-1}$ ); (b) $v\left(\right.$ color; $\left.\mathrm{m} \mathrm{s}^{-1}\right)$; (c) $w\left(\mathrm{~mm} \mathrm{~s}^{-1}\right.$; note nonlinear color scale); (d) magnitude of surface stress vector $\left|\boldsymbol{\tau}_{s}\right| / \rho_{0}$ ( solid black), zonal surface stress $\tau_{\mathrm{sx}} / \rho_{0}$ (blue), meridional surface stress $\tau_{s y} / \rho_{0}$ (green), and SST (dashed; right axis). In (a) $-(\mathrm{c})$, the potential temperature [white contours; contour interval $(\mathrm{CI})=0.5^{\circ} \mathrm{C}$ ] and MABL height (solid black line) are also shown. In (c), the dashed line indicates the length scale $2 \pi \bar{U} / f$. The abscissa is the same for each plot.

Monin-Obukhov similarity theory is used to compute surface fluxes of momentum and heat according to Blackadar (1976) and Zhang and Anthes (1982); the surface stress is given by

$$
\tau_{s}=\rho_{0} C_{\mathrm{Da}}\left|\mathbf{u}_{a}\right| \mathbf{u}_{a},
$$

where $\mathbf{u}_{a}$ is the wind at the lowest model level $\left(z_{a} \approx 6 \mathrm{~m}\right)$ and the drag coefficient is computed as

$$
C_{\mathrm{Da}}=\left[\frac{k}{\ln \left(z_{a} / z_{0}\right)-\psi_{m}}\right]^{2},
$$


where $k$ is the von Kármán constant, $z_{0}$ is the roughness length, and $\psi_{m}$ is a stability function (Blackadar 1976; Zhang and Anthes 1982). Note that $\left|\boldsymbol{\tau}_{s}\right| / \rho_{0}=u_{*}^{2}$, where $u_{*}$ is the friction velocity.

Our dry configuration precludes clouds, precipitation, and latent heating, which all contribute to the atmospheric response to midlatitude SST fronts (Minobe et al. 2008, 2010; Tokinaga et al. 2009; Chelton and Xie 2010; Kuwano-Yoshida et al. 2010; Czaja and Blunt 2011; Sasaki et al. 2012). Radiative fluxes are also absent. Other WRF options used here include implicit vertical velocity damping in the upper $5 \mathrm{~km}$ to absorb gravity waves (Klemp et al. 2008) and sixth-order horizontal viscosity to control computational noise.

The initial condition is $u=\bar{U}$, the geostrophic wind. This study considers model fields at $24 \mathrm{~h}$, at which time the MABL structure is nearly steady; although the MABL slowly deepens beyond $24 \mathrm{~h}$, the qualitative structure described in sections 4-6 does not change.

\section{Overview of lower atmosphere response to SST front}

a. Cold-to-warm case

Figure 2 shows the model winds, potential temperature $\theta$, and surface stress fields at $24 \mathrm{~h}$ for the cold-to-warm case $\left(\bar{U}=15 \mathrm{~m} \mathrm{~s}^{-1}\right)$. Overall, the fields are very similar to S07 (cf. his Fig. 2).

The top of the MABL (Figs. 2a-c, thick black line) is defined here as the height where the turbulent momentum flux [Eq. (5)] falls below $0.005 \mathrm{~m}^{2} \mathrm{~s}^{-2}$; this cutoff value is $2 \%-4 \%$ of the turbulent momentum flux at the surface, which ranges from 0.12 to $0.2 \mathrm{~m}^{2} \mathrm{~s}^{-2}$ (Fig. 4a). The MABL depth is $470 \mathrm{~m}$ in the equilibrium region upwind of the SST front (SST pattern shown in Fig. 2d), grows to $700 \mathrm{~m}$ over the downwind edge of the SST front, and continues increasing for hundreds of kilometers downwind, before settling at $850 \mathrm{~m}$.

Within the MABL, $\theta$ is well mixed in the downwind region over warm SST, while $\theta$ shows evidence of restratification in the upwind region over cool SST (Figs. $2 \mathrm{a}-\mathrm{c}$, white contours). Across the domain, the stratification is enhanced near the MABL top; directly above the SST front, there is a temperature inversion of about $0.3^{\circ} \mathrm{C}$ across the MABL top. A lateral temperature gradient within the MABL extends hundreds of kilometers downwind of the SST front due to heat advection by the strong winds.

The zonal wind $u$ (Fig. 2a) is nearly geostrophic above the MABL and slightly supergeostrophic near the top of the MABL. Above the SST front $(x=-100 \mathrm{~km}$ to $x=$ $100 \mathrm{~km}$ ), the mid and upper MABL $u$ decelerates, while the near-surface $u$ accelerates (Figs. 2a and 3a); the wind shear is therefore reduced, before recovering somewhat downwind. The surface wind divergence is positive in the region of positive downwind SST gradient, consistent with scatterometer measurements (Small et al. 2008; O'Neill et al.2010a). Downwind of $x=150 \mathrm{~km}$, the upper MABL $u$ recovers somewhat before the MABL reaches equilibrium with the warmer SST.

The meridional wind $v$ (Fig. 2b) is close to zero above the MABL, consistent with the prescribed zonal geostrophic wind. Within the MABL, $v$ develops upwind of the SST front due to the influence of friction and rotation. Near the MABL top, $v$ increases over warm SST as the MABL deepens. The surface $v$ shows little change across the SST front relative to the surface $u$ (Fig. 3a); the surface wind vector turns anticyclonically, consistent with O'Neill et al. (2010a,b).

The vertical wind $w$ field (Fig. 2c) can be divided into several distinct regions. Directly above the SST front $(x=-70 \mathrm{~km}$ to $x=0 \mathrm{~km})$, a region of descent with a maximum amplitude of $1-2 \mathrm{~mm} \mathrm{~s}^{-1}$ is confined to the lower half of the MABL. Stacked above this is a region of ascent $(x=-120 \mathrm{~km}$ to $x=120 \mathrm{~km})$, with a maximum amplitude of $2-4 \mathrm{~mm} \mathrm{~s}^{-1}$ near the MABL top. Extending downwind of the SST front are a region of descent ( $x=150 \mathrm{~km}$ to $x=700 \mathrm{~km})$ with a maximum amplitude of $1-2 \mathrm{~mm} \mathrm{~s}^{-1}$ near the MABL top and a weaker region of ascent extending east of $x=700 \mathrm{~km}$. The focus of this study is the latter ascent-descentascent signal that results from MABL depth-integrated convergence (section 5) and extends into the free atmosphere (section 6).

The surface stress magnitude $\left|\tau_{s}\right| / \rho_{0}$ increases by $58 \%$ across the SST front (Fig. 2d, black line), greatly exceeding the $9 \%$ increase in the drag coefficient (not shown). Thus, from the standpoint of the surface boundary condition [Eq. (9)], the increase in $\left|\tau_{s}\right| / \rho_{0}$ over warm SST is primarily associated with an increase in the surface wind speed (Fig. 3a), consistent with previous studies (Wai and Stage 1989; Small et al. 2003, 2008; Chelton and Xie 2010; S07). The increase in $\left|\tau_{s}\right| / \rho_{0}$ is due to the zonal component $\tau_{\mathrm{sx}} / \rho_{0}$, as the meridional component $\tau_{s y} / \rho_{0}$ shows little change ( $x=-200 \mathrm{~km}$ to $x=200 \mathrm{~km}$ in Fig. 2d); the surface wind stress divergence $\left(\boldsymbol{\nabla} \cdot \boldsymbol{\tau}_{s}\right)$ is thus positive in the region of positive downwind SST gradient, consistent with scatterometer measurements (O'Neill et al. 2003; Chelton et al. 2004; O'Neill et al. 2005; Song et al. 2009; Chelton and Xie 2010). We will show that this increase in $\tau_{\mathrm{sx}} / \rho_{0}$ across the SST front is dynamically linked to the $w$ signal at the top of the MABL (section 5a). Note that $\tau_{\mathrm{sx}} / \rho_{0}$ reaches a maximum between $x=100 \mathrm{~km}$ and $x=$ $400 \mathrm{~km}$ before gradually decreasing to an equilibrium value near $x=1100 \mathrm{~km}$. 

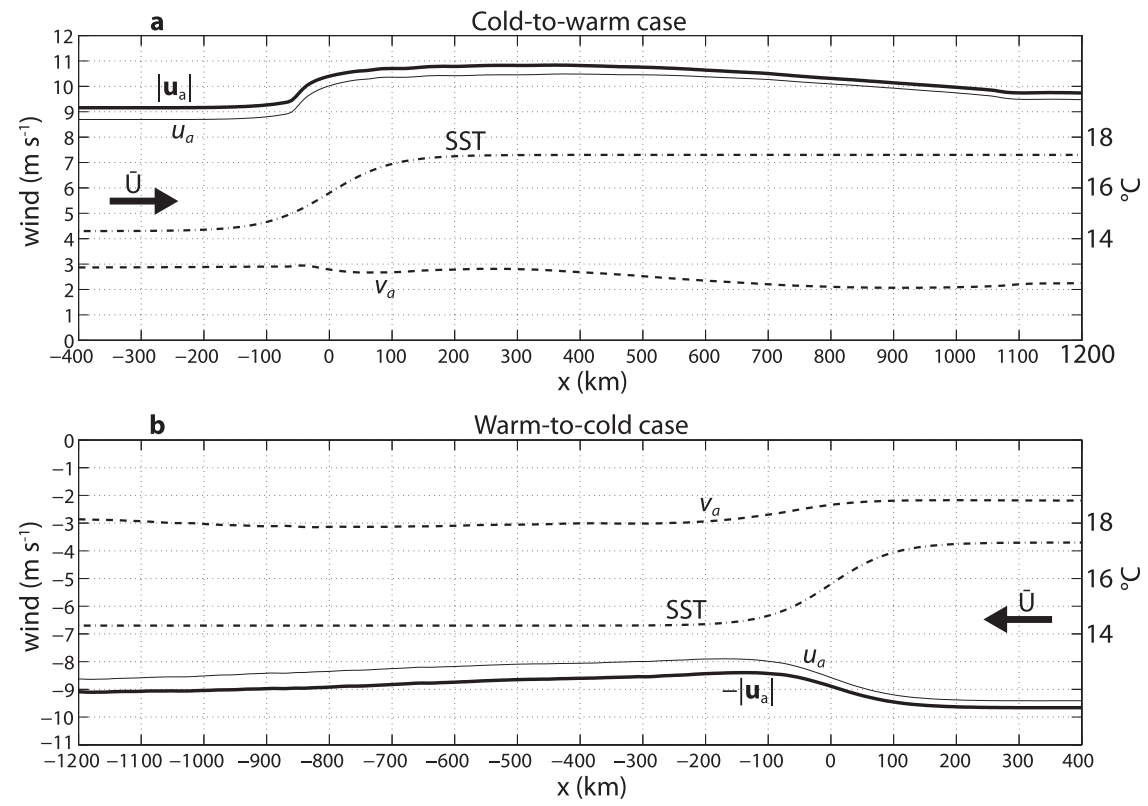

FIG. 3. Lowest model level $\left(z_{a} \approx 6 \mathrm{~m}\right)$ wind for the (a) cold-to-warm case $\left(\bar{U}=15 \mathrm{~m} \mathrm{~s}^{-1}\right)$ and (b) warm-to-cold case $\left(\bar{U}=-15 \mathrm{~m} \mathrm{~s}^{-1}\right)$ : zonal wind $u_{a}$ (thin solid), meridional wind $v_{a}$ (dashed), and wind speed $\left|\mathbf{u}_{a}\right|$ (thick solid) [the negative wind speed is shown in (b)]. The SST pattern is also shown (dashed-dotted; scale on right).

Figure 4a shows vertical profiles of the turbulent momentum flux [Eq. (5)] upwind of the SST front, near the center of the SST front, and over the downwind edge of the SST front. The downward turbulent momentum flux intensifies as the MABL deepens over warm SST, suggesting that the increase in surface stress across the SST front (Fig. 2d) is related to the vertical mixing mechanism (Wallace et al. 1989; Hayes et al. 1989). The vertical mixing coefficient $K_{M}$ increases dramatically over warm SST (Fig. 5a), where the air-sea heat flux turns positive (Fig. 8c) and causes buoyant production of turbulent kinetic energy (Nakanishi and Niino 2006).

\section{b. Warm-to-cold case}

Figure 6 shows the model fields at $24 \mathrm{~h}$ for the warmto-cold case $\left(\bar{U}=-15 \mathrm{~m} \mathrm{~s}^{-1}\right)$. We again see a change in the MABL depth across the SST front, from $850 \mathrm{~m}$ in the upwind region to $450 \mathrm{~m}$ in the far downwind region. Note that using a $\theta$ criterion for the MABL depth (rather than the turbulent momentum flux criterion) would indicate a dramatic collapse of the MABL across the SST frontal length scale, as a shallow stable internal boundary layer forms over cool SST (white contours in Figs. 6a-c), consistent with prior studies (Song et al. 2006; Skyllingstad et al. 2007, S07).

Again, the wind profile responds differently to the SST front $(x=100 \mathrm{~km}$ to $x=-300 \mathrm{~km})$ in the upper and lower parts of the MABL. The mid and upper MABL $u$ accelerates over cool SST, then decelerates farther downwind $(x=-300 \mathrm{~km}$ to $x=-900 \mathrm{~km})$ where the air has completely exited the MABL (Fig. 6a). A similar pattern occurs in $v$ (Fig. 6b), shifted downwind by a quarter wavelength, suggesting an inertial oscillation in a reference frame following the background wind $\bar{U}$ (section $5 \mathrm{~d}$ ). The horizontal divergence associated with this "inertial lee wave" (S07) results in a descentascent-descent pattern from $x=100 \mathrm{~km}$ to $x=-1000 \mathrm{~km}$ at 500-1000-m height (Fig. 6c; section 5d). Meanwhile the surface $u$ decelerates over cool SST (Figs. 6a and 3b); that is, the surface wind divergence associated with the negative downwind SST gradient is negative, consistent with scatterometer measurements (Small et al. 2008; O'Neill et al. 2010a). The surface wind vector turns cyclonically, consistent with O'Neill et al. (2010a,b).

The surface stress magnitude $\left|\boldsymbol{\tau}_{s}\right| / \rho_{0}$ decreases $34 \%$ over cool SST (Fig. 6d, black line), again exceeding the change that can be explained by the $8 \%$ decrease in the drag coefficient (not shown). The change in $\left|\boldsymbol{\tau}_{s}\right| / \rho_{0}$ is due mostly to the zonal component $\tau_{\mathrm{sx}} / \rho_{0}$ (Fig. $6 \mathrm{~d}$, blue line); $\boldsymbol{\nabla} \cdot \boldsymbol{\tau}_{s}<0$ in the region of negative downwind SST gradient, consistent with scatterometer measurements (O'Neill et al. 2003; Chelton et al. 2004; O'Neill et al. 2005; Song et al. 2009; Chelton and Xie 2010). The change in $\tau_{\mathrm{sx}} / \rho_{0}$ is again linked to the $w$ signal above the MABL (section 5b). Note that the magnitude of $\tau_{\mathrm{sx}} / \rho_{0}$ reaches a minimum near $x=-100 \mathrm{~km}$ before 

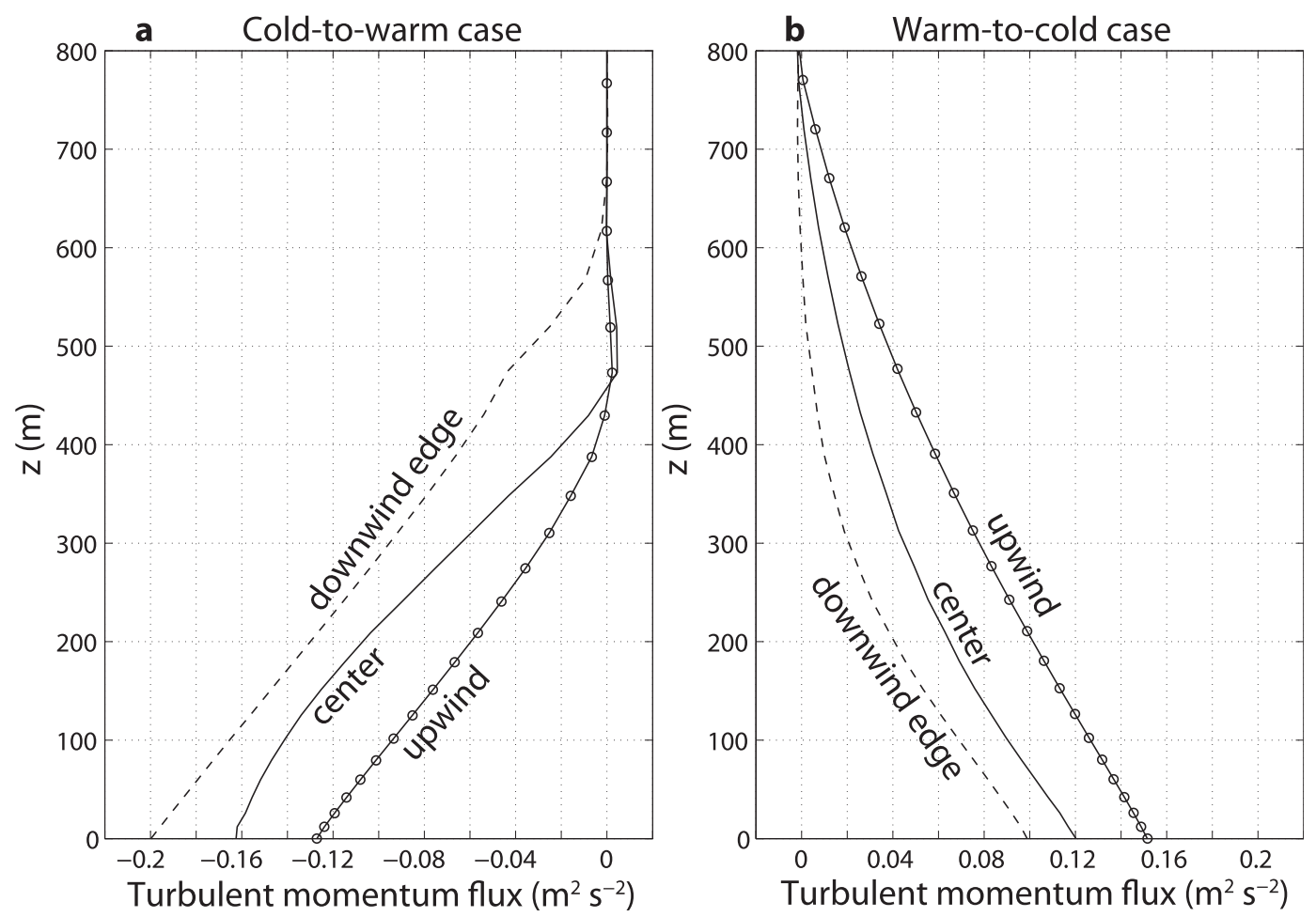

FIG. 4. Turbulent vertical flux of horizontal momentum [Eq. (5)] for the (a) cold-to-warm case $\left(\bar{U}=15 \mathrm{~m} \mathrm{~s}^{-1}\right)$ and (b) warm-to-cold case $\left(\bar{U}=-15 \mathrm{~m} \mathrm{~s}^{-1}\right)$. Vertical profiles are given upwind of the SST front, near the center of the SST front, and over the downwind edge of the SST front. In (a) the longitudes are $x=-300,-36$, and $150 \mathrm{~km}$, respectively; in (b) the longitudes are $x=300,6$, and $-150 \mathrm{~km}$, respectively. Circles indicate model levels.

recovering somewhat toward an equilibrium value near $x=-1100 \mathrm{~km}$.

Figure $4 \mathrm{~b}$ shows vertical profiles of the turbulent momentum flux [Eq. (5)] upwind of the SST front, near the center of the SST front, and over the downwind edge of the SST front. The downward turbulent momentum flux weakens as the MABL shrinks over cool SST; Samelson et al. (2006, cf. their Fig. 5) show similar results for a large-eddy simulation of the warm-to-cold case. The stabilizing air-sea heat flux over cool SST (Fig. 11c) reduces the turbulent kinetic energy and the vertical mixing coefficient $K_{M}$ (Fig. 5b).

\section{Mechanisms of boundary layer convergence}

a. IBL-like region for cold-to-warm case

\section{1) THE $u$ BUDGET}

The zonal (cross-front) momentum equation solved by WRF consists of the following terms:

$$
\partial_{t} u=\underbrace{-u \partial_{x} u-w \partial_{z} u}_{\mathrm{Adv}}+\underset{\mathrm{Cor}}{f v}-\rho_{\mathrm{PG}}^{-1} \partial_{x} p+\rho_{0}^{-1} \partial_{z} \tau_{x} .
$$

The $u$ tendency (lhs) is effectively zero for the quasisteady MABL structure considered here. The rhs is comprised of advection (Adv), Coriolis (Cor), pressure gradient (PG), and turbulent stress divergence (TSD) terms; note that the meridional advection vanishes because $\partial_{y} u=0$ in our two-dimensional configuration.

A section of the Eq. (11) terms is shown in Fig. 7 for the cold-to-warm case $\left(\bar{U}=15 \mathrm{~m} \mathrm{~s}^{-1}\right)$. Note that a positive advection tendency is equivalent to $u \partial_{x} u<0$ and indicates that the flow is decelerating. Upwind of the SST front the TSD term acts as a drag on the wind and balances the Coriolis term, consistent with an Ekman momentum balance (S07; cf. his Fig. 9). From $x=$ $-50 \mathrm{~km}$ to $x=80 \mathrm{~km}$, the advection and TSD terms show large, opposing responses to the SST front: the mid and upper MABL wind decelerates as the drag by the TSD term is enhanced, and the reverse occurs in the lower MABL, where the near-surface wind accelerates as the drag by the TSD term diminishes. This reversal in the vertical structure in the TSD term is consistent with the vertical mixing mechanism (e.g., Skyllingstad et al. 2007; O'Neill et al. 2010b). Note that the magnitude of the advection term is comparable to the magnitude of the Coriolis term, indicating that $\epsilon=O(1)$; the strong 

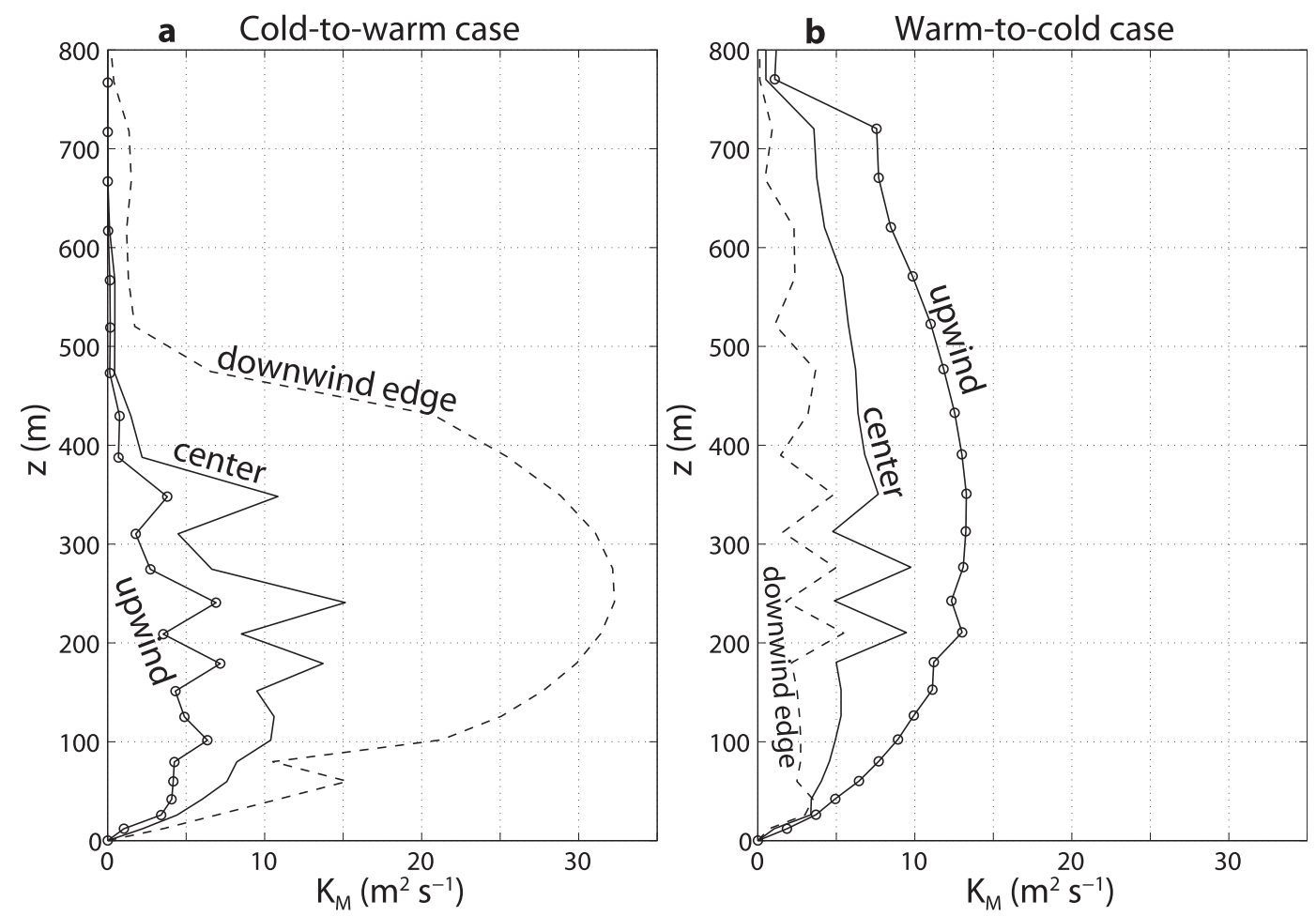

FIG. 5. Vertical mixing coefficient for momentum $K_{M}(z)\left(\mathrm{m}^{2} \mathrm{~s}^{-1}\right)$ for the (a) cold-to-warm case $\left(\bar{U}=15 \mathrm{~m} \mathrm{~s}^{-1}\right)$ and (b) warm-to-cold case $\left(\bar{U}=-15 \mathrm{~m} \mathrm{~s}^{-1}\right)$. Vertical profiles are given at the same locations as in Fig. 4. Circles indicate model levels.

influence of advection is to be expected directly above the SST front, where the MABL has not yet reached equilibrium with the warmer SST (Samelson et al. 2006; S07). The Coriolis and pressure gradient terms show smaller changes that develop over a longer length scale.

Figure 8 compares the $u$ budget [Eq. (11)] at one model level in the upper MABL to the surface (cf. Fig. 10 in S07). The upper MABL zonal wind (Fig. 8a) begins to decelerate near $x=-50 \mathrm{~km}$ because of the enhanced drag by the TSD term. The Coriolis term grows over a longer length scale as the meridional wind spins up, and the wind is fully equilibrated to the warmer SST by $x=900 \mathrm{~km}$.

In contrast, the surface zonal wind (Fig. 8b) accelerates sharply as the drag by the TSD term vanishes near $x=-50 \mathrm{~km}$. [Note that although the turbulent stress divergence vanishes, the surface stress increases sharply (Fig. 2d, blue line), consistent with the turbulent momentum flux profile in Fig. 4a.] The pressure gradient term begins to increase near $x=0 \mathrm{~km}$, while the TSD term recovers and exceeds its upwind value, counteracting the pressure gradient term; the momentum balance downwind of $x=100 \mathrm{~km}$ is reminiscent of the "pressure-drag" mechanism of Small et al. (2005), also discussed in O'Neill et al. (2010b). The surface wind is fully equilibrated to the warmer SST at $x=$ $1100 \mathrm{~km}$. However, most of the increase in $u$ occurs before $x=0 \mathrm{~km}$ (Fig. 3a), where the pressure gradient term is negligible and the Coriolis term is nearly constant (Fig. 8b). We conclude that the change in the TSD term above the SST front (relative to the upwind region) effectively accelerates the surface zonal wind, similar to some previous studies (Skyllingstad et al. 2007; O'Neill et al. 2010b). Note that this behavior is consistent with the S07 description of the surface zonal wind increasing via the unbalanced Coriolis force, or "Coriolis torque," since the Coriolis term remains near its upwind value as the drag by the TSD term vanishes (Fig. 8b).

Figures 7 and 8 indicate that the upwind Ekman momentum balance is disrupted above the SST front by the altered TSD term. From $x=-100 \mathrm{~km}$ to $x=0 \mathrm{~km}$, the perturbation momentum balance is

$$
0=-u \partial_{x} u-w \partial_{z} u+\rho_{0}^{-1} \partial_{z} \Delta \tau_{x} .
$$

Equation (12) is obtained by subtracting the upwind Ekman momentum balance, $0=f v+\rho_{0}^{-1} \partial_{z} \tau_{x}$, from Eq. (11); $\Delta \tau_{x}$ is the SST-induced change in stress. Equation (12) represents nonrotating, internal boundary layer 

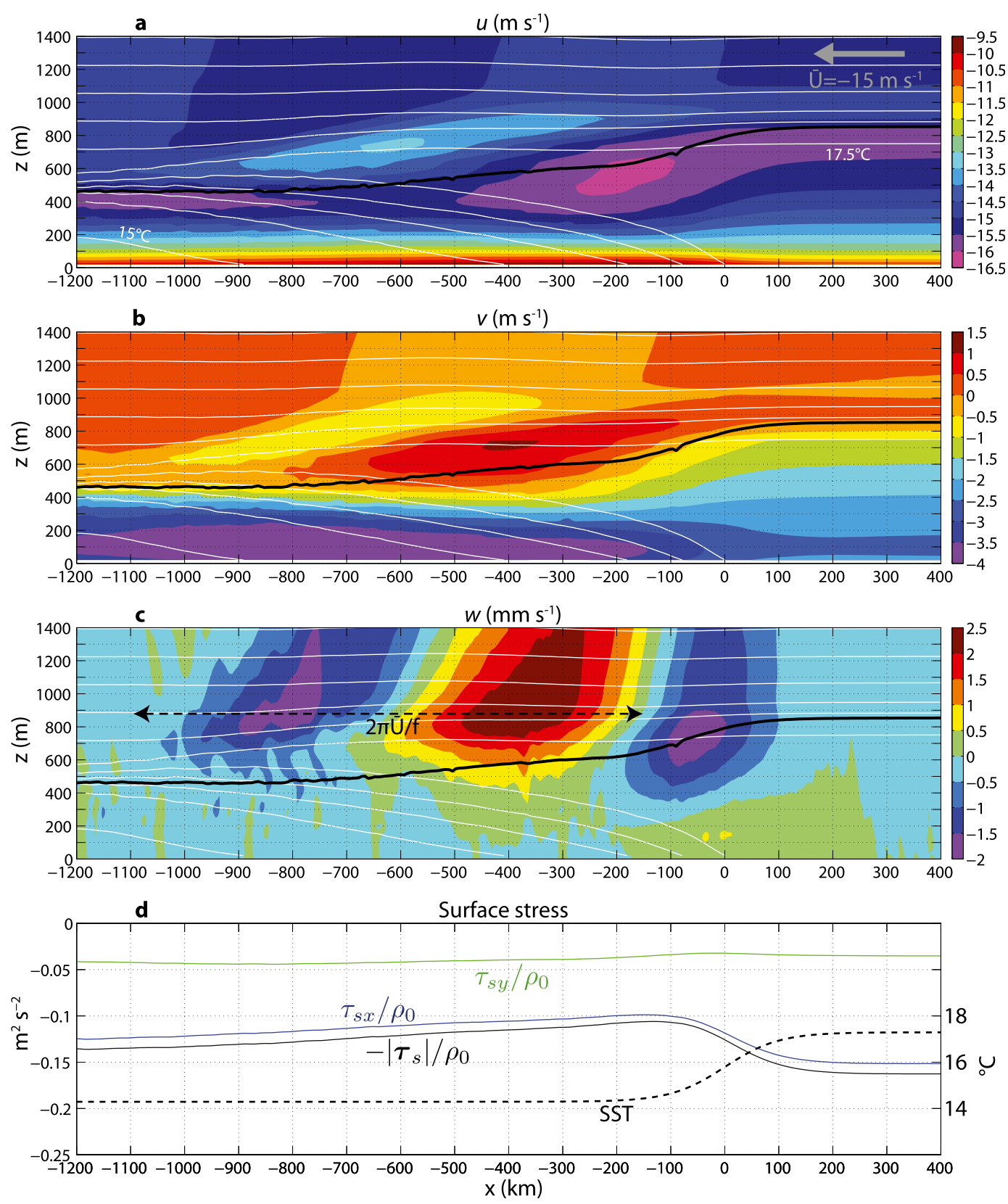

FIG. 6. As in Fig. 2, but for the warm-to-cold case $\left(\bar{U}=-15 \mathrm{~m} \mathrm{~s}^{-1}\right)$. In (d), the solid black line shows the negative magnitude of the surface stress, $-\left|\boldsymbol{\tau}_{s}\right| / \rho_{0}$.

(IBL)-like physics (Garratt 1990), wherein advection balances the TSD.

\section{2) MABL DEPTH-INTEGRATED CONVERGENCE}

To understand the MABL depth-integrated convergence, it is helpful to consider the vertical integral of Eq. (11) from the surface to $h=800 \mathrm{~m}$, which is above or near the top of the MABL for the cold-to-warm case. Moving the advection terms to the lhs,

$$
\int_{0}^{h} d z\left(u \partial_{x} u+w \partial_{z} u\right)=f \int_{\text {Cor }}^{h} d z v-\int_{0}^{h} d z \rho_{\text {PG }}^{-1} \partial_{x} p-\rho_{0}^{-1} \tau_{s x} .
$$

The TSD term reduces to the surface stress on the rhs of Eq. (13) because $\tau_{x}$ vanishes at $z=h$.

Figure 9a shows the terms in Eq. (13). Note that the lhs of Eq. (13) is very close to the sum of the rhs terms 

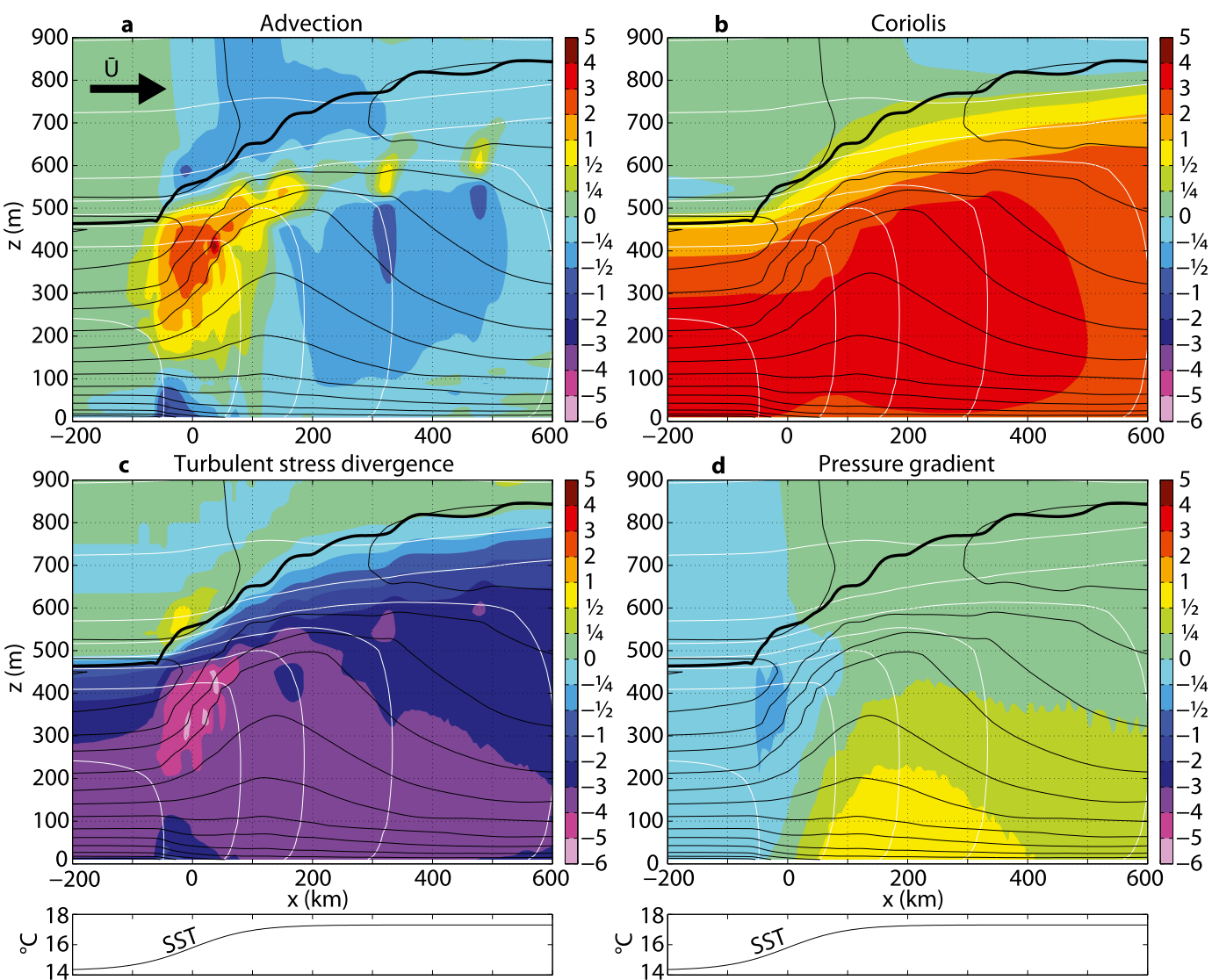

FIG. 7. Sections of zonal momentum budget terms $\left(\times 10^{-4} \mathrm{~m} \mathrm{~s}^{-2}\right.$; note nonlinear color scale) in Eq. (11) for the cold-to-warm case $\left(\bar{U}=15 \mathrm{~m} \mathrm{~s}^{-1}\right.$ ): (a) advection; (b) Coriolis force; (c) turbulent stress divergence; and (d) pressure gradient. The thick black line marks the top of the MABL, the thin black lines are $u$ contours $\left(\mathrm{CI}=0.5 \mathrm{~m} \mathrm{~s}^{-1}\right)$, and the white lines are $\theta$ contours $\left(\mathrm{CI}=0.5^{\circ} \mathrm{C}\right)$. SST is shown in the bottom panels.

(cf. Adv and Rhs in Fig. 9a), indicating that the MABL structure is nearly steady. The surface stress acts as a drag on the depth-integrated wind and balances the Coriolis term in the equilibrium regions upwind and far downwind (past $x=1000 \mathrm{~km}$ ) of the SST front, just as the surface stress balances the cross-isobar transport in a linear bottom Ekman layer (Svensson and Holtslag 2009). The advection term turns negative directly above the SST front (Fig. 9a; $x=-100 \mathrm{~km}$ to $x=0 \mathrm{~km}$ ), balanced primarily by the enhanced surface stress; the pressure gradient and Coriolis terms do not show large changes until after $x=0 \mathrm{~km}$. Thus the MABL depthintegrated wind is retarded from $x=-100 \mathrm{~km}$ to $x=$ $0 \mathrm{~km}$, due to the enhanced drag by the surface stress.

The advection term in Eq. (13) can be simplified in two steps. The first step is to ignore the vertical advection since $\left|\int_{0}^{h} d z w \partial_{z} u\right| \ll\left|\int_{0}^{h} d z u \partial_{x} u\right|$ (not shown). The second step is to split $u$ into its geostrophic and ageostrophic components: $u=\bar{U}+u^{\prime}$. In the MABL depth integral, advection by $\bar{U}$ dominates advection by $u^{\prime}$ for the strong cross-front winds considered here (not shown), and the lhs of Eq. (13) can be approximated by $\bar{U} \int_{0}^{h} d z \partial_{x} u^{\prime}$. Thus the depth-integrated advection term (Adv in Fig. 9) corresponds very closely to the depth-integrated divergence, and from $x=-100 \mathrm{~km}$ to $x=0 \mathrm{~km}$ Eq. (13) may be approximated by

$$
\bar{U} \int_{0}^{h} d z \partial_{x} u^{\prime}=-\rho_{0}^{-1} \Delta \tau_{\mathrm{sx}} .
$$

Equation (14) is obtained by subtracting the upwind, Ekman-like balance, $0=f \int d z v-\rho_{0}^{-1} \tau_{\mathrm{sx}}$, from Eq. (13); the surface stress increment $\Delta \tau_{\mathrm{sx}}$ is relative to the upwind value. Equation (14) corresponds to a MABL depth integral of the IBL-like momentum equation [Eq. (12)].

Substituting the continuity equation into the lhs of Eq. (14) yields

$$
\bar{U} w_{h}=\rho_{0}^{-1} \Delta \tau_{\mathrm{sx}},
$$

where $w_{h}$ is the vertical velocity at $z=h$. The surface stress increment $\Delta \tau_{\mathrm{sx}}$ therefore diagnoses $w_{h}$; this 

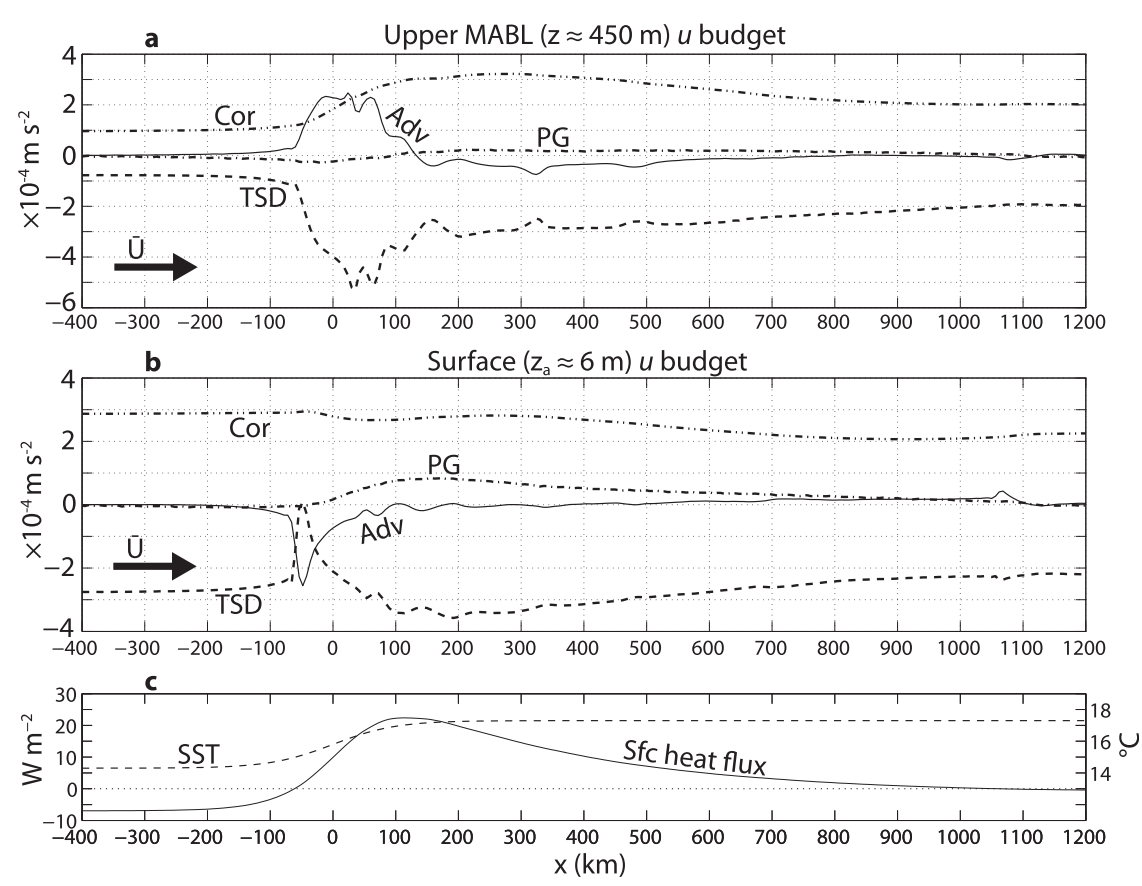

FIG. 8. Zonal momentum budget terms for the cold-to-warm case $\left(\bar{U}=15 \mathrm{~m} \mathrm{~s}^{-1}\right)$ at two model levels: (a) upper MABL $(z \approx 450 \mathrm{~m})$ and (b) surface $\left(z_{a} \approx 6 \mathrm{~m}\right)$. The budget terms are labeled as in Eq. (11). (c) The surface sensible heat flux $\left(\mathrm{W} \mathrm{m}^{-2}\right.$; positive upward) and SST.

important relation is a consequence of the IBL-like physics [Eq. (12)] that prevail directly above the SST front. At $x=0 \mathrm{~km}, \rho_{0}^{-1} \Delta \tau_{\mathrm{sx}}=0.057 \mathrm{~m}^{2} \mathrm{~s}^{-2}$ (Fig. 9a, dashed line), so that the vertical velocity diagnosed from Eq. (15) is $\rho_{0}^{-1} \Delta \tau_{\mathrm{sx}} / \bar{U}=3.8 \mathrm{~mm} \mathrm{~s}^{-1}$, consistent with the $3-4 \mathrm{~mm} \mathrm{~s}^{-1}$ ascent above the MABL (Fig. 2c).

Although the simple IBL-like physics [Eqs. (14) and (15)] do not hold past $x=0 \mathrm{~km}$, the lhs of Eq. (13) is well approximated by $\bar{U} w_{h}$ for the whole domain; that is, Fig. 9 a identifies the direct contributions to $w_{h}$ of all three terms on the rhs of Eq. (13). From $x=0 \mathrm{~km}$ to $x=100 \mathrm{~km}$ the increase in the pressure gradient and Coriolis contributions reverse the sign of $w_{h}$ (Fig. 9a). Note that the pressure gradient contribution changes sign near $x=$ $0 \mathrm{~km}$. The reason for this is clear in Fig. $7 \mathrm{~d}$ : the convective deepening of the MABL causes a reversal of the pressure gradient in the upper MABL (Hashizume et al. 2002; Small et al. 2005, 2008; Song et al. 2006). Downwind of the SST front, the pressure gradient term turns positive but is counteracted by the enhanced drag by the surface stress, reminiscent of the MABL depth-integrated pressure drag of O'Neill et al. (2010b). The pressure gradient term remains positive to $x=1100 \mathrm{~km}$.

\section{3) INTERPRETATION OF VERTICAL MIXING MECHANISM}

The MABL response is qualitatively very similar to $\mathrm{S} 07$ [who used the Coupled Ocean-Atmosphere Mesoscale
Prediction System (COAMPS) model rather than WRF], but we differ with $\mathrm{S} 07$ in our interpretation of the vertical mixing mechanism's role in the MABL response (Wallace et al. 1989; Hayes et al. 1989). S07 downplayed the vertical mixing mechanism and emphasized the redistribution of momentum between the meridional and zonal winds via the Coriolis force. However, in our interpretation the IBL-like physics described above, which dominate the MABL response from $x=-100 \mathrm{~km}$ to $x=$ $0 \mathrm{~km}$, are consistent with the vertical mixing mechanism. This view is supported by the following:

- A pattern of momentum loss by the mid and upper MABL wind, and momentum gain by the surface wind, that reduces the wind shear (Fig. 7, black contours). Momentum budgets indicate that changes in the turbulent stress divergence term (relative to the upwind region) are responsible for the altered wind profile.

- A sharp increase in the cross-front component of the surface stress, indicating an enhanced turbulent momentum flux to the surface (Figs. 2d, 4a).

- An increase in the vertical mixing coefficient $K_{M}$ (Fig. 5a) that is caused by the upward air-sea heat flux over warm SST (Fig. 8).

The Coriolis term is present in the momentum budgets but is largely static in the IBL-like region (Figs. 8 and 9). Although the surface wind response to the SST front is consistent with the Coriolis torque described by 
S07, the Coriolis force alone cannot explain the increase in surface wind speed across the SST front (Fig. 3a), since the Coriolis force can only act to rotate the wind. The increases in surface wind speed and $\left|\boldsymbol{\tau}_{s}\right|$ over warm SST are robust features of scatterometer measurements [e.g., Fig. 4 in O'Neill et al. (2005) and Figs. 4-7 in O'Neill et al. (2012)].

\section{b. IBL-like region for warm-to-cold case}

A section of the $u$ budget terms [Eq. (11)] for the warmto-cold case $\left(\bar{U}=-15 \mathrm{~m} \mathrm{~s}^{-1}\right)$ is shown in Fig. 10 (cf. Fig. 7 in S07). Note that a positive advection tendency is equivalent to $u \partial_{x} u<0$ and indicates that the flow is accelerating, since the background wind is now easterly. Upwind of the SST front the TSD term acts as a drag on the wind and balances the Coriolis term, consistent with an Ekman momentum balance. From $x=100 \mathrm{~km}$ to $x=-150 \mathrm{~km}$, the advection and TSD terms again show large, opposing responses to the SST front. In this case, the mid and upper MABL wind accelerates as the drag by the TSD term diminishes over cool SST, while the reverse occurs near the surface. The Coriolis and pressure gradient terms change over a longer length scale.

Figure 11 compares the $u$ budget at one model level in the upper MABL to the surface (cf. Fig. 8 in S07). In the upper MABL (Fig. 11a), the wind begins to accelerate near $x=150 \mathrm{~km}$ in response to the diminished drag by the TSD term. The TSD term eventually goes to zero; the Coriolis and advection terms oscillate downwind in opposing fashion, consistent with the inertial lee wave described by S07. The surface zonal wind (Fig. 11b) begins decelerating near $x=150 \mathrm{~km}$ in response to the enhanced drag by the TSD term. [Note that although the turbulent stress divergence is magnified, the surface stress weakens (Fig. 6d, blue line), consistent with Fig. 4b.] The response of the surface wind in this IBL-like region is analogous to how, in the cold-to-warm case, the depthintegrated wind is retarded because of the enhanced drag by the surface stress (Fig. 9a). The pressure gradient also acts to retard the surface zonal wind starting near $x=0 \mathrm{~km}$, playing a greater role than in the cold-towarm case. The surface wind is equilibrated to the cooler SST at about $x=-700 \mathrm{~km}$.

The depth-integrated momentum budget for the warmto-cold case indicates that above the SST front $(x=150 \mathrm{~km}$ to $x=0 \mathrm{~km})$, the depth-integrated wind accelerates because of the diminished drag by the surface stress (Fig. 9b), consistent with the IBL-like physics discussed above. Above the SST front the Coriolis term remains close to its upwind value and changes downwind over a longer length scale. Note that this behavior is analogous to the surface wind response in the cold-to-warm case,
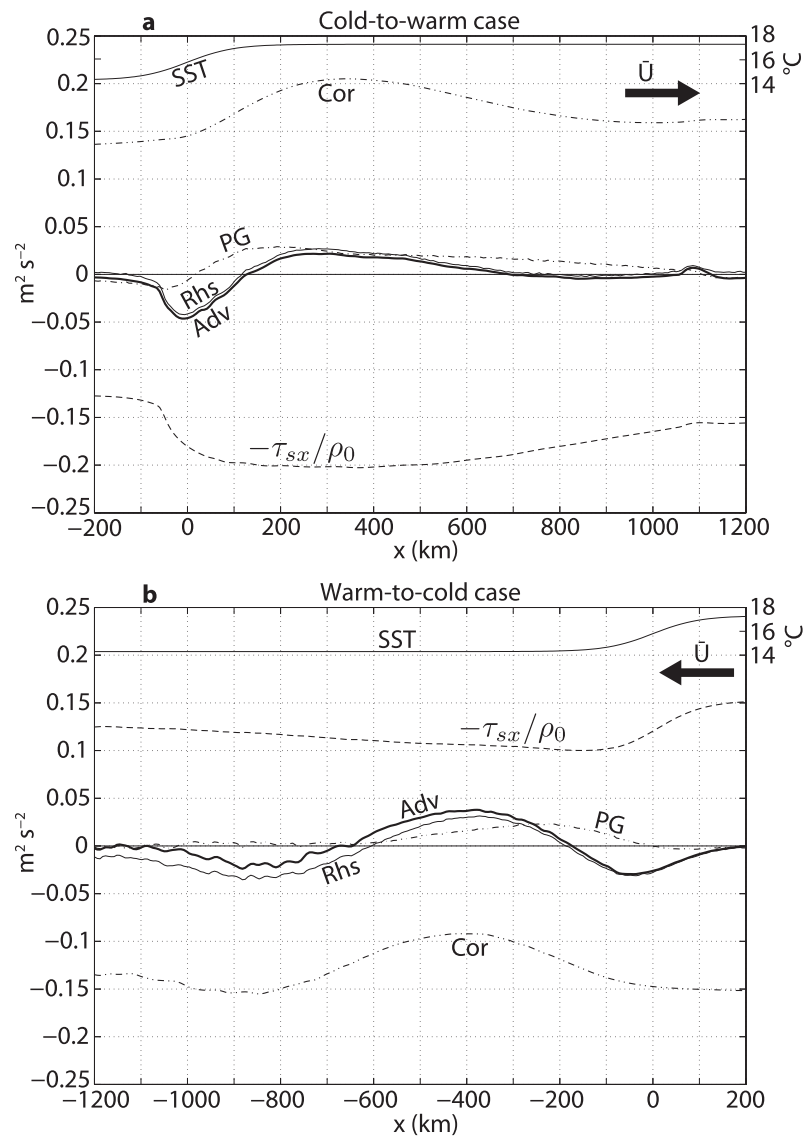

FIG. 9. Depth integral of $u$ budget [Eq. (13)] from surface to $h=$ $800 \mathrm{~m}$ for the (a) cold-to-warm case $\left(\bar{U}=15 \mathrm{~m} \mathrm{~s}^{-1}\right)$ and (b) warmto-cold case $\left(\bar{U}=-15 \mathrm{~m} \mathrm{~s}^{-1}\right)$. Here "Rhs" is the sum of the rhs terms in Eq. (13).

where the surface wind accelerates in response to the diminished drag by the TSD term (Fig. 8b).

The surface stress $\tau_{\mathrm{sx}}$ changes more gradually here than in the cold-to-warm case, and the magnitude of the convergence signal is smaller (cf. Figs. 9a,b). Similar to the cold-to-warm case, the Coriolis and pressure gradient contributions cause a reversal of $w_{h}$ near $x=-170 \mathrm{~km}$.

\section{c. Diagnosing vertical motion from Eq. (15)}

We test Eq. (15) for a suite of cases, with $\bar{U}$ varying from -30 to $30 \mathrm{~m} \mathrm{~s}^{-1}$. For each case, the maximum $w_{h}$ above the SST front is compared with the vertical velocity estimate $\rho_{0}^{-1} \Delta \tau_{\mathrm{Sx}} / \bar{U}$ based on Eq. (15) (Fig. 12). The estimates are very good for the cold-to-warm cases $(\bar{U}>0)$ : within $10 \%$ of $w_{h}$ for $\bar{U}>6 \mathrm{~m} \mathrm{~s}^{-1}$, reproducing the roughly linear increase with $\bar{U}$. Note that $w_{h}$ is inversely related to $\bar{U}$ based on Eq. (15), so the linear relationship in Fig. 12 implies that $\Delta \tau_{\mathrm{sx}}$ increases quadratically 

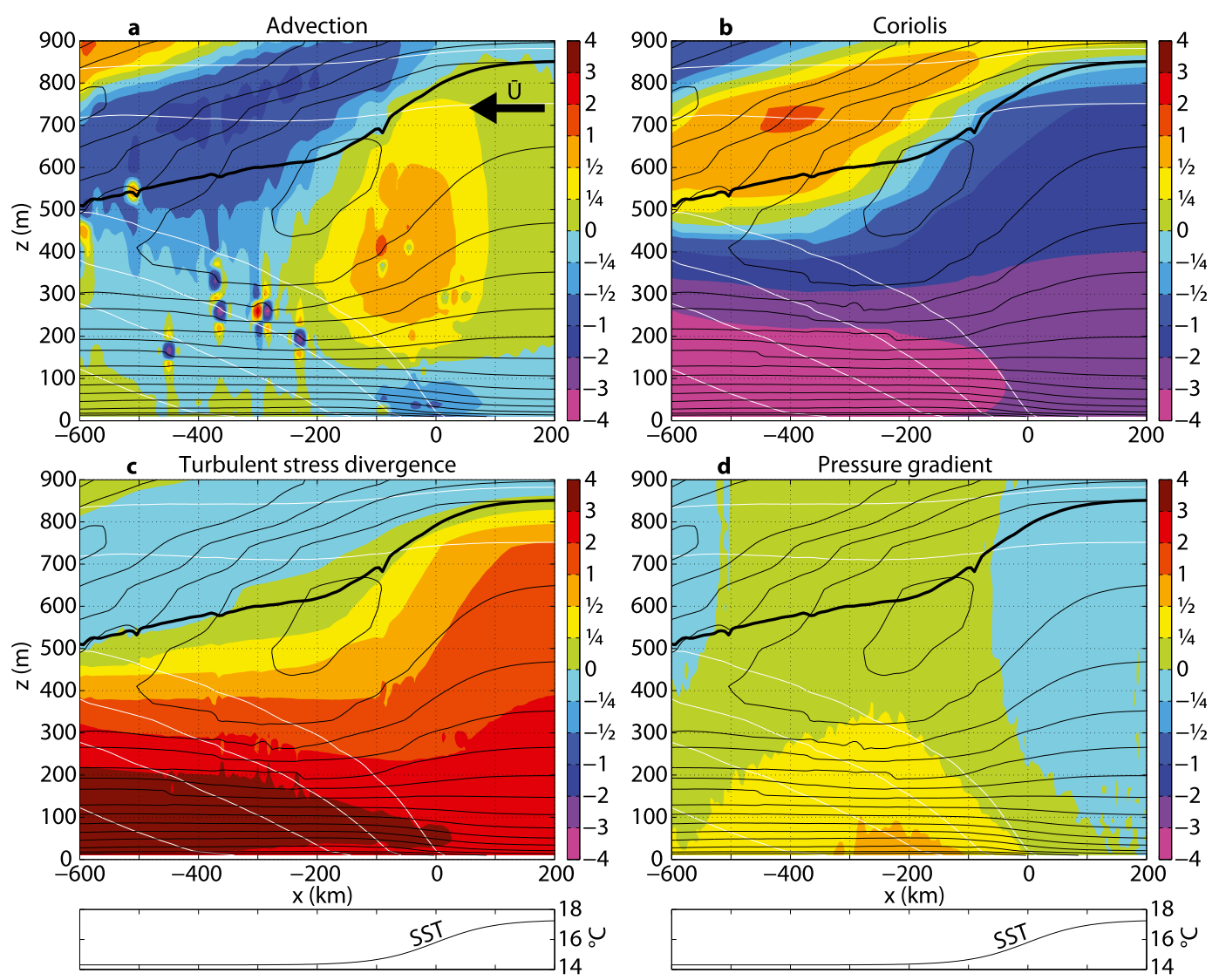

FIG. 10. As in Fig. 7, but for the warm-to-cold case $\left(\bar{U}=-15 \mathrm{~m} \mathrm{~s}^{-1}\right)$. Note nonlinear color scale. The grid-scale (in the vertical) numerical instabilities visible in (a) tend to appear near the top of the shallow internal boundary layer and are advected downwind.

with $\bar{U}$, consistent with the quadratic relationship found for the coupling coefficient in S07 (see his Fig. 6).

For the warm-to-cold cases $(\bar{U}<0)$, Eq. (15) systematically overestimates the amplitude of $w_{h}$, although the estimates are generally better for larger wind speeds (Fig. 12). The warm-to-cold estimates of $w_{h}$ are poor because the changes in the TSD term and $\tau_{\mathrm{sx}} / \rho_{0}$ are not as sharp compared to the cold-to-warm cases (Figs. 7-11), so the pressure gradient and Coriolis terms play relatively larger roles in the depth-integrated momentum budget (Fig. 9), and the IBL physics approximation underlying Eq. (15) is not as accurate.

\section{d. Downwind region and inertial oscillations}

Sign reversals in $w_{h}$ continue downwind of the SST front in both cases, with a wavelength of approximately $2 \pi \bar{U} / f$ (length scale marked in Figs. $2 c$ and $6 c$ ). This downwind $w_{h}$ signal results from inertial oscillations in a reference frame moving with the background wind speed $\bar{U}$, described as an "inertial lee wave" for the warm-to-cold case by S07. Note that the downwind $w_{h}$ signal is weaker for the cold-to-warm case (cf. Figs. 2c and $6 \mathrm{c}$ ), presumably because the inertial oscillations occur within the MABL and are therefore more quickly damped than in the warm-to-cold case.

\section{e. SLP adjustment mechanism}

The importance of the advection terms in the MABL response to the SST front would seem to preclude the Ekman-type models of MABL convergence discussed in section 2, but we nonetheless check for the pressure adjustment mechanism [Eqs. (2) and (3)]. The SLP Laplacian $\nabla^{2} p_{s}$, surface wind convergence $\delta_{a}=-\partial_{x} u_{a}$ depth-averaged wind convergence $\bar{\delta}=-h^{-1} \int_{0}^{h} d z \partial_{x} u$ (with $h=800 \mathrm{~m}$ ), and SST are shown for the cold-towarm case (Fig. 13a) and warm-to-cold case (Fig. 13b).

The $\nabla^{2} p_{s}$ signal is of the same sign as $\delta_{a}$ above the SST front $(x=-100 \mathrm{~km}$ to $x=100 \mathrm{~km})$, consistent with Eq. (3), as is often found in satellite observations and GCMs (Minobe et al. 2008, 2010; Kuwano-Yoshida et al. 2010; Bryan et al. 2010; Shimada and Minobe 2011). However, $\delta_{a}$ and $\bar{\delta}$ have the opposite sign [confounding the mixed-layer assumption of Eqs. (2) and (3)], so that Eq. (3) predicts the wrong sign of the depth-integrated 

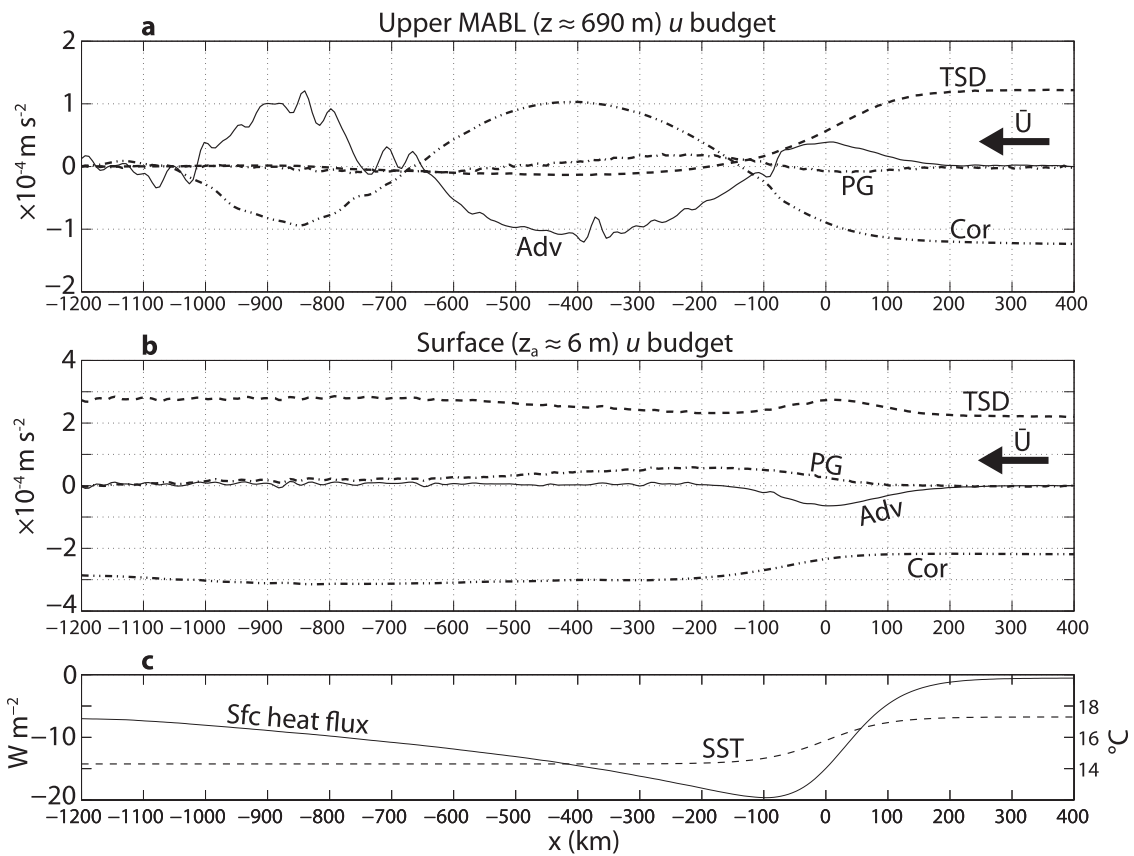

FIG. 11. As in Fig. 8, but for the warm-to-cold case $\left(\bar{U}=-15 \mathrm{~m} \mathrm{~s}^{-1}\right)$.

convergence. The failure of Eqs. (2) and (3) is not surprising, because we have already seen that for the strong cross-front winds considered here, MABL convergence is primarily a function of the lateral heterogeneity in turbulent mixing, or IBL-like physics (Fig. 9), rather than pressure adjustments. Satellite observations also indicate that the pressure adjustment mechanism weakens when crossfront winds are strong (Shimada and Minobe 2011).

\section{f. MABL adjustment to Ekman balance}

We have considered the MABL adjustment to the SST front in terms of the momentum balance but it is also useful to consider the relative vorticity. For a MABL that approximates an Ekman momentum balance, the relative vorticity is given by the horizontal divergence of Eq. (1),

$$
\zeta=\underbrace{\frac{\nabla^{2} p}{\rho_{0} f}}_{\zeta_{G}} \underbrace{-\frac{1}{\rho_{0} f} \frac{\partial}{\partial z}(\nabla \cdot \tau)}_{\zeta_{F}},
$$

such that $\zeta$ has a geostrophic component $\left(\zeta_{G}\right)$ related to the Laplacian of the pressure and a frictional component $\left(\zeta_{F}\right)$ related to the horizontal divergence of the stress.

We have computed depth averages of the terms in Eq. (16) from the surface to a fixed level above the MABL for three cold-to-warm cases of different background wind speeds. For the base case with $\bar{U}=15 \mathrm{~m} \mathrm{~s}^{-1}$ (Fig. 14a), $\bar{\zeta}$ does not resemble $\bar{\zeta}_{G}+\bar{\zeta}_{F}$ at all, as $\bar{\zeta}_{G}+\bar{\zeta}_{F}$ is far too large from $x=-100 \mathrm{~km}$ to $x=0 \mathrm{~km}$ and is the wrong sign from $x=0 \mathrm{~km}$ to $x=150 \mathrm{~km}$. This is consistent with analyses that indicate the MABL does not approximate an Ekman momentum balance for the $\bar{U}=15 \mathrm{~m} \mathrm{~s}^{-1}$ case (section 5a). For $\bar{U}=6 \mathrm{~m} \mathrm{~s}^{-1}$ (Fig. 14b), $\bar{\zeta}$ does more closely resemble $\bar{\zeta}_{G}+\bar{\zeta}_{F}$, although substantial differences remain, especially above the SST front $(x=$ $-100 \mathrm{~km}$ to $x=100 \mathrm{~km}$ ). For $\bar{U}=2 \mathrm{~m} \mathrm{~s}^{-1}$ (Fig. 14c), $\bar{\zeta}$ approximates $\bar{\zeta}_{G}+\bar{\zeta}_{F}$ very well, suggesting the MABL has adjusted to an Ekman momentum balance for this weak-wind case. Note that $\bar{\zeta}_{G}$ and $\bar{\zeta}_{F}$ nearly cancel above the SST front $(x=-100 \mathrm{~km}$ to $x=100 \mathrm{~km})$, while $\bar{\zeta}$ approximates $\bar{\zeta}_{G}$ downwind of $x=100 \mathrm{~km}$, hinting at the importance of the pressure adjustment mechanism (Lindzen and Nigam 1987; Minobe et al. 2008). The mean advection is still strong enough to displace the pressure signal $\left(\bar{\zeta}_{G}\right)$ about $100 \mathrm{~km}$ downwind of the SST front. The progressive weakening of $\bar{\zeta}_{G}$ with $\bar{U}$ is apparently due to the weaker surface heat fluxes at low wind speeds (not shown).

Figure 14a shows that the MABL depth-averaged relative vorticity for strong cross-front winds, $\epsilon=O(1)$, does not satisfy Eq. (16), just as the momentum budget does not satisfy an Ekman momentum balance (see sections 5a and 5b). The concept of an Ekman layer requires an Ekman momentum balance [Eq. (1)] to first order in $\epsilon$ (Mahrt 1975; Beare and Cullen 2012), so the MABL convergence discussed in sections 5a-d should not be interpreted as Ekman pumping. However, for 


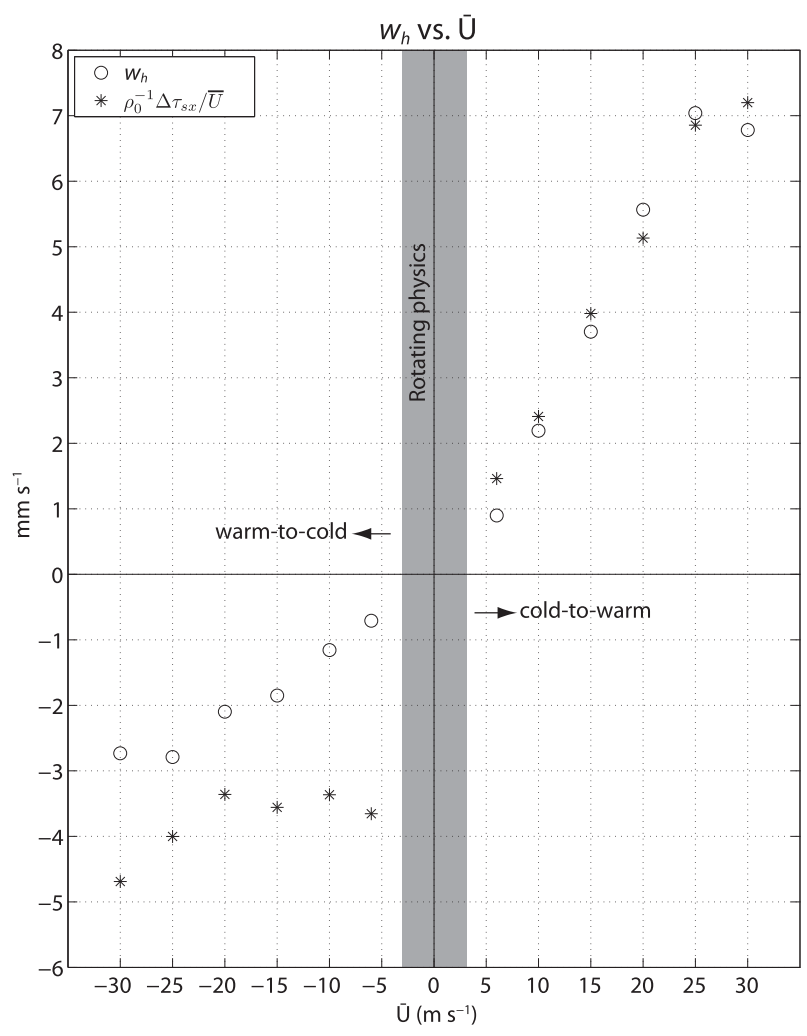

FIG. 12. Shown are $w_{h}$ (circles) and the vertical velocity estimate $\rho_{0}^{-1} \Delta \tau_{\mathrm{sx}} / \bar{U}$ based on Eq. (15) (stars); $\bar{U}>0$ for the cold-to-warm cases and $\bar{U}<0$ for the warm-to-cold cases. The region around $\bar{U}=0$ is shaded to indicate that nonrotating, IBL-like physics are not valid for weak cross-front winds.

weak cross-front winds $(\epsilon \ll 1)$, air parcels apparently cross the SST front slowly enough for the MABL to adjust to an Ekman momentum balance (Fig. 14c).

\section{Free atmosphere response to SST front}

The base cold-to-warm case's $w(x, z)$ field for the full $20-\mathrm{km}$ depth of the model (Fig. 15a) shows the characteristic pattern of a stationary internal gravity wave, with $w$ oscillating in the vertical and phase lines tilting upwind. In this section we use basic mountain wave theory (see appendix) to show that the atmosphere has a similar response to a change in topography.

The type of stationary wave response to an idealized, vertically uniform wind $\bar{U}$ blowing over a change in topography with wavenumber $k$ is determined by the "intrinsic frequency" $\tilde{\omega}=\bar{U} k$ (Durran 1990). We use $\bar{U}=$ $15 \mathrm{~m} \mathrm{~s}^{-1}$ and $k=(100 \mathrm{~km})^{-1}$, corresponding to the length scale of the SST front. Thus $\tilde{\omega} \sim f$, corresponding to a hydrostatic rotating gravity wave, which satisfies Eq. (A7) (Gill 1982, section 8.8). [The downwind inertial lee wave discussed in section $5 \mathrm{~d}$ has an intrinsic frequency very close to $\bar{U} k=f$, which produces a singularity in Eq. (A10); therefore, we ignore the free atmosphere response to the downwind inertial lee wave and focus on the contribution of the IBL-like region directly above the SST front.]

The wave solution $w(x, z)$ to Eq. (A7) can be found via Eq. (A11) if the lower boundary condition $w(x, 0)$ is specified. The linearized lower boundary condition for mountain waves is $w(x, 0)=\bar{U} \partial_{x} h$, where $h(x)$ is the topography (there is no boundary layer in the mountain wave problem considered here); for comparison to the SST front, we consider

$$
h(x)=\frac{h_{m}}{2} \tanh \left(\frac{x}{L_{T}}\right)
$$

where $h_{m}=80 \mathrm{~m}$ is the change in elevation [cf. Eq. (4)], such that the maximum topographic slope is $\partial_{x} h=4 \times$ $10^{-4}$. The Fourier transform of the lower boundary condition is

$$
\hat{w}(k, 0)=\bar{U} i k \hat{h},
$$

where $\hat{h}(k)$ is the Fourier transform of Eq. (17) (Bracewell 2000):

$$
\hat{h}(k)=-\frac{i h_{m} L_{T}}{2} \operatorname{csch}\left(\frac{\pi k L_{T}}{2}\right) .
$$

Equations (18) and (19) are substituted into Eq. (A11), which is evaluated numerically to produce the mountain wave solution shown in Fig. 15b.

The waves in Figs. 15a and 15b have similar amplitude and structure, indicating that an SST increase of $3^{\circ} \mathrm{C}$ over $200 \mathrm{~km}$ has a similar effect to an $80-\mathrm{m}$ change in topography. Note that the vertical scale of each wave is reduced above $12 \mathrm{~km}$, due to the increased stratification above the tropopause; the vertical wavelength is of order $2 \pi \bar{U} / N$ [Eq. (A10)], or $9.4 \mathrm{~km}$ in the troposphere and $4.5 \mathrm{~km}$ in the stratosphere for our configuration. The gravity wave response for the warm-to-cold case is similar but phase lines tilt eastward with height since $\bar{U}<0$ (not shown).

Although $80 \mathrm{~m}$ is a modest change in topography, larger-amplitude gravity waves are expected over western boundary current regions, where SST gradients can be much stronger than that used here. A more realistic mean wind profile could induce wave breaking that in turn would influence the mean wind through gravity wave drag (Durran 1990; Kim et al. 2003).

Observational evidence for SST-forced gravity waves is lacking, but other modeling studies have shown a gravity wave response similar to Fig. 15. Song et al. (2008) 

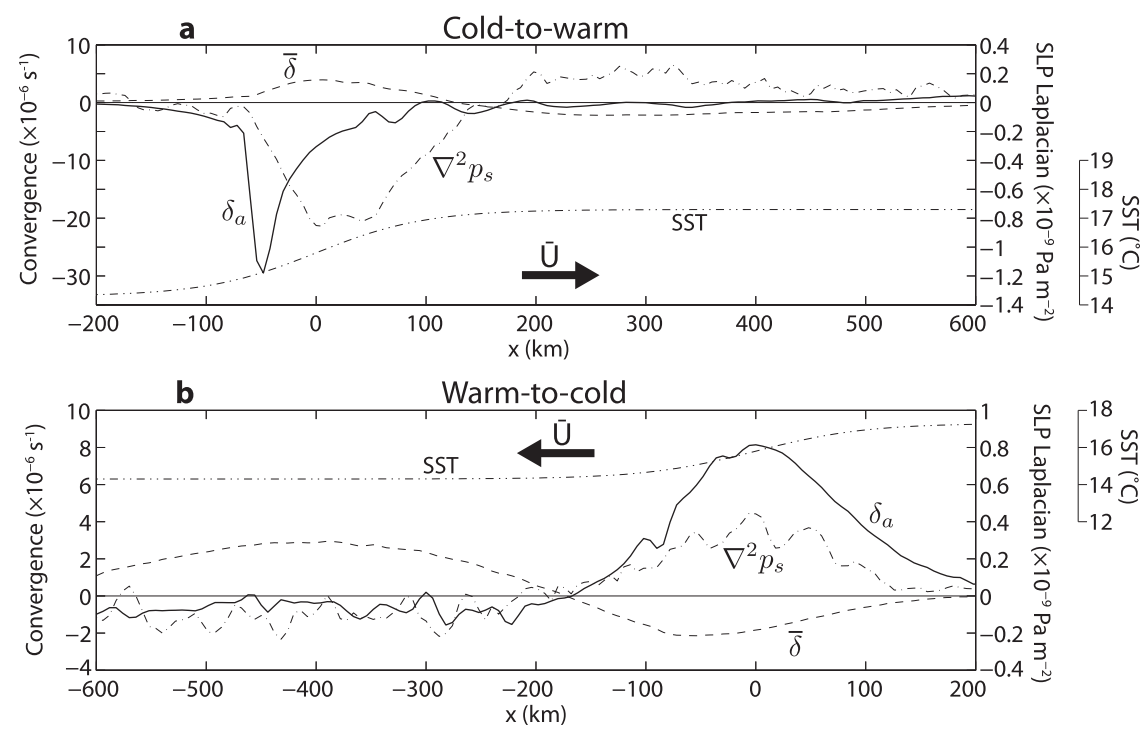

FIG. 13. Lowest model level wind convergence $\delta_{a}$, depth-averaged wind convergence $\bar{\delta}$, SLP Laplacian $\nabla^{2} p_{s}$, and SST for the (a) cold-to-warm case $\left(\bar{U}=15 \mathrm{~m} \mathrm{~s}^{-1}\right)$ and (b) warm-to-cold case $\left(\bar{U}=-15 \mathrm{~m} \mathrm{~s}^{-1}\right)$. Note that the vertical scale of the wind convergence (lhs) is several times larger in (a).

recognize a gravity wave forced by an SST "bump" in two-dimensional WRF experiments similar to ours. They estimate a $3^{\circ} \mathrm{C}$ change in SST has an effect comparable to a $200-\mathrm{m}$ hill, which is 2.5 times our estimate of $80 \mathrm{~m}$; this discrepancy could be due to the choice of turbulent mixing scheme or the length scale of the SST front (i.e., the SST gradient). Song et al. (2006, their Figs. 4 and 5) show MABL structure and vertical motion similar to ours using a realistic configuration over the Gulf Stream with the Fifth-Generation Pennsylvania State University-National Center for Atmospheric Research Mesoscale Model (MM5), but they interpret the vertical motion as a "system of up and downdrafts" rather than a gravity wave. Feliks et al. (2010) find a standing wave pattern ${ }^{1}$ in their simulation of the coldto-warm case, but they focus on a thermally direct cell with ascending air over warm SST and descending air over cool SST (Wai and Stage 1989), similar to a sea breeze; note that we do not see this type of pressure-forced "secondary circulation" (section 5), consistent with Song et al. (2006).

\section{Summary and discussion}

The atmospheric response to SST fronts is explored here with the WRF regional atmospheric model in an

\footnotetext{
${ }^{1}$ The reduced vertical wavelength of the Feliks et al. (2010) standing wave $(1.5 \mathrm{~km})$ relative to ours $(9.4 \mathrm{~km})$ is consistent with their weaker cross-front background wind $\left(3 \mathrm{~m} \mathrm{~s}^{-1}\right)$.
}

idealized, two-dimensional configuration similar to S07. The primary focus is on cases with strong cross-front background winds, $O\left(10 \mathrm{~m} \mathrm{~s}^{-1}\right)$, such that the crossfront Rossby number $\epsilon=O(1)$. Advection strongly influences the MABL for these cases, as found in previous studies (Small et al. 2005, 2008; Song et al. 2006; Skyllingstad et al. 2007; O'Neill et al. 2010b, S07). In both the cold-to-warm and warm-to-cold cases, the MABL response directly above the SST front is distinguished by a perturbation momentum balance between advection and turbulent stress divergence [see sections 5a(1) and 5b]. These nonrotating, IBL-like physics (Garratt 1990) are closely related to the vertical mixing mechanism (Wallace et al. 1989; Hayes et al. 1989); this is our only major disagreement with S07 [section 5a(3)], who argues instead for the importance of the Coriolis terms in redistributing momentum between the zonal and meridional winds.

In the cold-to-warm case, the MABL depth-integrated wind is retarded due to the enhanced drag by the surface stress $\left(\boldsymbol{\nabla} \cdot \boldsymbol{\tau}_{s}>0\right)$, resulting in net convergence and ascent at the top of the MABL (Fig. 9a); in the warm-to-cold case, the MABL depth-integrated wind is effectively accelerated as the drag by the surface stress is diminished $\left(\boldsymbol{\nabla} \cdot \boldsymbol{\tau}_{s}<0\right)$, resulting in net divergence and descent at the top of the MABL (Fig. 9b). Since the advection term corresponds closely to the divergence for the strong cross-front winds considered here, the change in the cross-front component of the surface stress diagnoses the MABL depth-integrated 

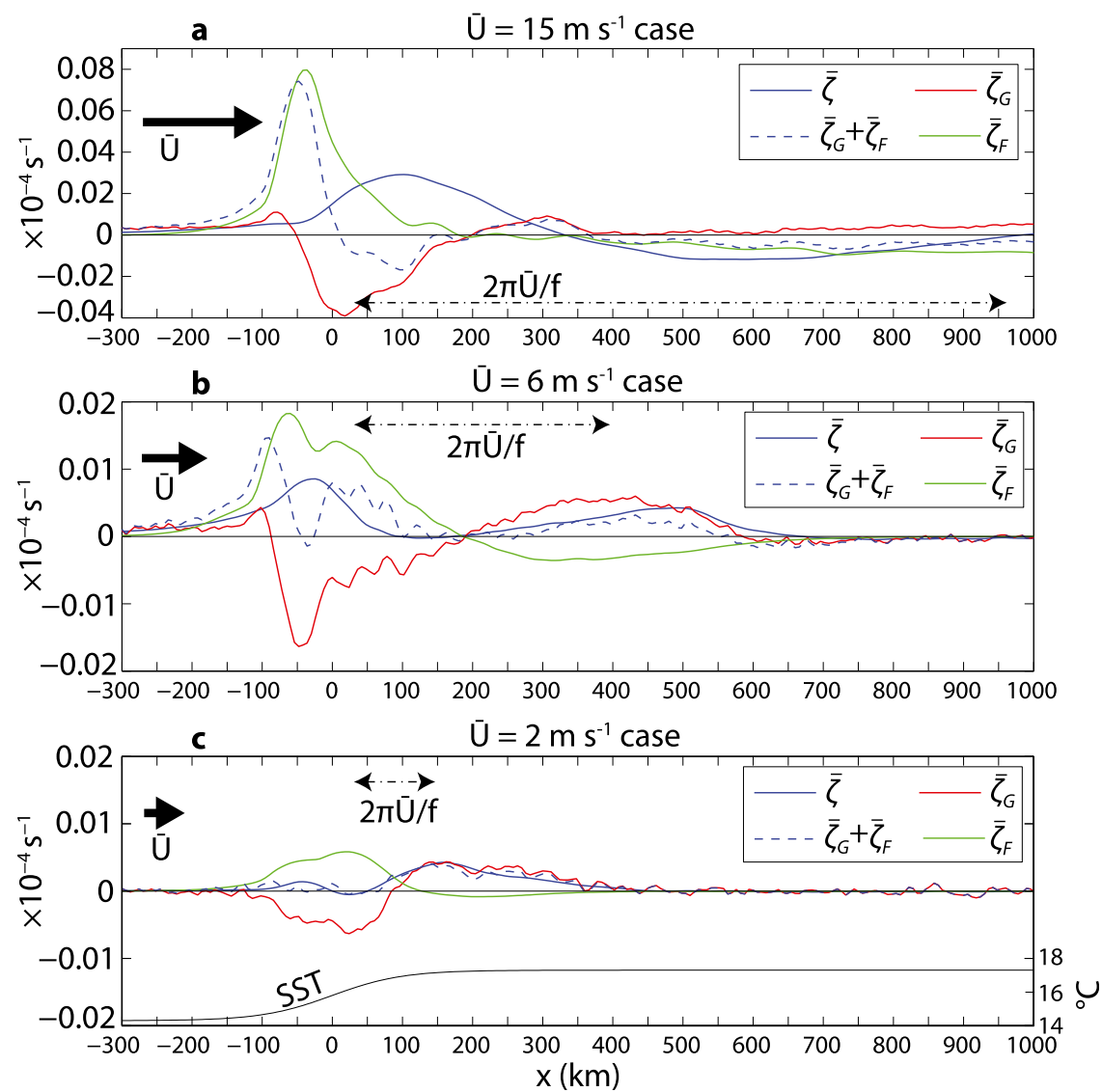

FIG. 14. MABL depth-averaged relative vorticity $\bar{\zeta}$ for the cold-to-warm cases with (a) $\bar{U}=15 \mathrm{~m} \mathrm{~s}^{-1}$, (b) $\bar{U}=6 \mathrm{~m} \mathrm{~s}^{-1}$, and (c) $\bar{U}=2 \mathrm{~m} \mathrm{~s}^{-1}$. The geostrophic $\left(\bar{\zeta}_{G}\right)$ and frictional $\left(\bar{\zeta}_{F}\right)$ components are also shown [see Eq. (16)]. The depth averages are computed from the surface to a fixed height above the MABL: 920,670 , and $390 \mathrm{~m}$, respectively. The length scale $2 \pi \bar{U} / f$ is marked in each panel. Note that the ordinates of (b) and (c) use a different scale from (a). SST is shown in (c) (right ordinate).

convergence and vertical velocity at the top of the MABL $^{2}$ [Eq. (15)].

For the strong cross-front winds considered here, the MABL depth-integrated convergence above the SST front is the opposite sign of the surface wind convergence (Fig. 13), calling into question the mixed-layer assumption that the MABL depth-integrated convergence corresponds to the surface wind convergence (Minobe et al. 2008, 2010; Joyce et al. 2009; Bryan et al. 2010; Kuwano-Yoshida et al. 2010; Shimada and Minobe 2011).

Following S07 and Small et al. (2008), it is helpful to consider the disparate length scales of the MABL

\footnotetext{
${ }^{2}$ This is analogous to a linear bottom Ekman layer, where the wind stress curl is a diagnostic measure of the depth-integrated boundary layer convergence and Ekman pumping velocity (Beare 2007).
}

response to the SST front: $L_{M}=U D_{M}^{2} / K_{M}$ for the turbulent stress divergence term, $L_{P}=U D_{H}^{2} / K_{H}$ for the pressure gradient term, and $L_{i}=U / f$ for the Coriolis term. The existence of an IBL-like region directly above the SST front indicates $L_{M}<L_{P}, L_{i}$ for the strong crossfront winds considered here (Figs. 7, 8, 10, and 11). In particular, the disparity between $L_{M}$ and $L_{P}$ is due to the different depth scales for momentum and temperature $\left(D_{M} \ll D_{H}\right)$, since the vertical mixing coefficients $K_{M, H}$ are comparable (not shown); the wind profile has significant shear within the MABL, in contrast to the relatively well-mixed temperature (S07). The clear separation between $L_{M}$ and $L_{P}$ in our simulations has allowed us to focus on the changes to the turbulent stress divergence and surface stress. However, more realistic modeling studies of both equatorial (Small et al. 2003, 2005) and midlatitude (Song et al. 2006; O'Neill et al. 2010b) regions have shown that the pressure gradient term can be comparable to or even dominate the turbulent stress 

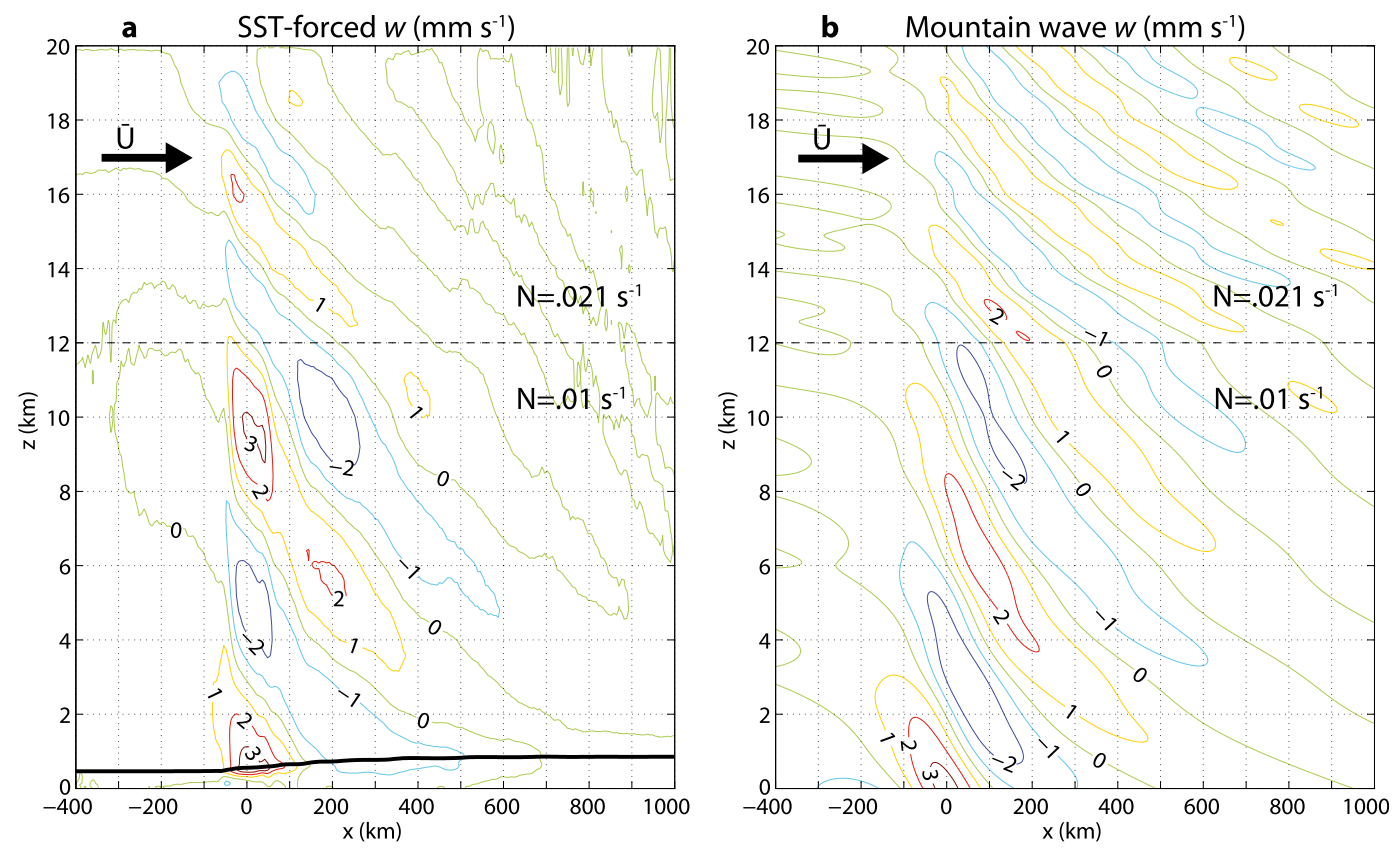

FIG. 15. Vertical motion $w$ (colored contours; $\mathrm{mm} \mathrm{s}^{-1}$ ) for the (a) cold-to-warm WRF simulation (as in Fig. 2c) and (b) comparable mountain wave. The MABL height is marked in (a) by the thick black line. Dashed lines indicate the tropopause and arrows indicate the mean wind $\bar{U}=15 \mathrm{~m} \mathrm{~s}^{-1}$.

divergence term in the surface momentum budget; the generality of the IBL-like physics discussed in section 5 is therefore unclear.

The influence of advection on the MABL dynamics can be characterized by $\epsilon$. For strong cross-front winds, $\epsilon=O$ (1), indicating that advection dominates the cross-front momentum budget. When $\epsilon=O(1)$, the MABL does not approximate an Ekman momentum balance [Eq. (1)] and Ekman-type models of MABL convergence that have been proposed for SST frontal zones (section 2) are not appropriate: the MABL convergence discussed in section 5 is not Ekman pumping, but rather is a consequence of the lateral heterogeneity in turbulent mixing.

Our results therefore appear to contradict Brachet et al. (2012), who considered the atmospheric response to the Gulf Stream in a GCM and found the 10-day averaged fields to be consistent with the Feliks et al. (2004) MABL model. This discrepancy may be due to the different time scales involved; we consider the MABL response to an SST front that occurs over a few hours for strong cross-front winds, while Brachet et al. (2012) and other studies (Minobe et al. 2008, 2010; Bryan et al. 2010; Kuwano-Yoshida et al. 2010; Shimada and Minobe 2011; Takatama et al. 2012) consider atmospheric fields averaged over longer times in realistic GCMs and the real atmosphere. It is possible that the Ekman-type models hold approximately for time-averaged fields of the time-varying atmosphere, but further research is necessary to fully resolve this discrepancy.

For strong cross-front winds, the free atmosphere responds to the SST-forced vertical motion as a stationary internal gravity wave, very much like a mountain wave or lee wave. An analytical solution to the internal gravity wave equation (Fig. 15) shows that an SST front of $3^{\circ} \mathrm{C}$ over $200 \mathrm{~km}$ excites a gravity wave comparable to an 80-m change in topography. Following basic mountain wave theory (Gill 1982; Durran 1990), the free atmosphere wave response is determined by the "intrinsic frequency" $\tilde{\omega}=\bar{U} k$, where $\bar{U}$ is the cross-front wind speed and $k$ is the dominant horizontal wavenumber of the SST front. For the strong cross-front winds considered here, $\tilde{\omega} \sim f$, corresponding to the hydrostatic rotating wave limit. Note that this is a fundamentally different response from the Ekman pumping mechanism of Feliks et al. (2004), as linear inertia-gravity waves carry no potential vorticity (e.g., Lien and Müller 1992) and therefore are not "felt" by the balanced, synoptic-scale flow. The SST-forced gravity waves can only influence the synoptic-scale flow through nonlinear processes like wave breaking.

The patterns of boundary layer convergence and vertical motion studied here are specific to cases of strong cross-front winds (Fig. 1). For the alongfront wind case, air parcels cross the SST front slowly $(\epsilon \ll 1)$ and the character of the MABL response changes: the 
SST-induced pressure gradient is larger because the MABL temperature adjusts to SST over a smaller crossfrontal length scale (S07; Small et al. 2008), and the MABL approximates an Ekman momentum balance (Fig. 14c). Thus the MABL physics will more closely resemble Ekman models in which the MABL temperature mirrors SST (Feliks et al. 2004; Minobe et al. 2008). In the free atmosphere $\tilde{\omega} \ll f$ (equivalent to $\epsilon \ll 1$ ), corresponding to the quasigeostrophic or "spindown" limit considered by Feliks et al. (2004); gravity waves are absent and the response is evanescent, decaying in the vertical over a Rossby height $f L / N$. The coupling coefficient for wind stress divergence and downwind SST gradient is systematically larger than the coupling coefficient for wind stress curl and crosswind SST gradient, although both coupling coefficients vary considerably across SST frontal zones (Chelton et al. 2001, 2004; Chelton and Xie 2010; O'Neill et al. 2003, 2005); we hypothesize that the systematic difference between the two coupling coefficients is due to the fundamentally different MABL physics for cases of cross-front winds and alongfront winds.

Acknowledgments. We thank two anonymous reviewers and Dr. Michael Spall for comments and suggestions that helped improve the manuscript. We also thank Drs. Shang-Ping Xie, Eric Firing, Roger Lukas, Peter Müller, and Gary Barnes for valuable discussions. This research was supported by the National Science Foundation through Grants OCE-0550233, OCE-0647994, and OCE-0926594. WRF experiments were performed at the International Pacific Research Center (IPRC) parallel computing facility, where Ron Merrill and Dave Burns provided assistance. The IPRC is sponsored by the Japan Agency for Marine-Earth Science and Technology (JAMSTEC), by NASA through Grant NNX07AG53G, and by NOAA through Grant NA17RJ1230.

\section{APPENDIX}

\section{Mountain Waves}

Following Durran (1990) the Boussinesq linearized equations of motion are

$$
\begin{array}{r}
\bar{U} \frac{\partial u}{\partial x}-f v+\frac{\partial P}{\partial x}=0, \\
\bar{U} \frac{\partial v}{\partial x}+f u=0, \\
\bar{U} \frac{\partial w}{\partial x}+\frac{\partial P}{\partial z}=b,
\end{array}
$$

$$
\begin{gathered}
\bar{U} \frac{\partial b}{\partial x}+N^{2} w=0, \\
\frac{\partial u}{\partial x}+\frac{\partial w}{\partial z}=0,
\end{gathered}
$$

where the buoyancy $b=g\left(\theta-\theta_{0}\right) / \theta_{s}, P=c_{p} \theta_{s}\left(\pi-\pi_{0}\right)$, and $N^{2}=\left(g / \theta_{s}\right) d \theta_{0} / d z$. The Exner function pressure is $\pi=\left(p / p_{s}\right)^{R / c_{p}}$. The basic-state pressure and potential temperature are $\pi_{0}(z)$ and $\theta_{0}(z)$, while $p_{s}$ and $\theta_{s}$ are reference values.

Equations (A1)-(A5) combine to form one equation for $w$ :

$$
\bar{U}^{2} \frac{\partial^{2}}{\partial x^{2}}\left[\frac{\partial^{2} w}{\partial x^{2}}+\frac{\partial^{2} w}{\partial z^{2}}\right]+N^{2} \frac{\partial^{2} w}{\partial x^{2}}+f^{2} \frac{\partial^{2} w}{\partial z^{2}}=0
$$

In the hydrostatic approximation $\partial / \partial x \ll \partial / \partial z$ and the left term in the brackets of Eq. (A6) is neglected (Gill 1982, section 8.8), leaving

$$
\left(\bar{U}^{2} \frac{\partial^{2}}{\partial x^{2}}+f^{2}\right) \frac{\partial^{2} w}{\partial z^{2}}+N^{2} \frac{\partial^{2} w}{\partial x^{2}}=0 .
$$

If the one-dimensional Fourier transform of a function $\psi(x, z)$ is defined as

$$
\hat{\psi}(k, z)=\frac{1}{\pi} \int_{-\infty}^{\infty} d x \psi(x, z) e^{-i k x},
$$

then the Fourier transform of Eq. (A7) yields

$$
\left(-\bar{U}^{2} k^{2}+f^{2}\right) \frac{\partial^{2} \hat{w}}{\partial z^{2}}-k^{2} N^{2} \hat{w}=0 .
$$

Assuming a solution of the form $\hat{w}(k, z)=\hat{w}(k, 0) e^{m z}$,

$$
m=\frac{i k N}{\sqrt{\bar{U}^{2} k^{2}-f^{2}}},
$$

which yields a vertically propagating wave for $\bar{U} k>f$ and an evanescent wave for $\bar{U} k<f$.

For an arbitrary lower boundary condition $w(x, 0)$ with Fourier representation $\hat{w}(k, 0)$, the solution to Eq. (A7) is obtained via the inverse Fourier transform:

$$
\begin{gathered}
w(x, z) \\
=\operatorname{Re}\left[\int_{f / \bar{U}}^{\infty} d k \hat{w}(k, 0) \exp \left\{i k N z\left(\bar{U}^{2} k^{2}-f^{2}\right)^{-1 / 2}\right\} e^{i k x}\right] . \\
\text { (A11) } \\
\text { REFERENCES }
\end{gathered}
$$

\section{REFERENCES}

Adamson, D. S., S. E. Belcher, B. J. Hoskins, and R. S. Plant, 2006 Boundary-layer friction in midlatitude cyclones. Quart. J. Roy. Meteor. Soc., 132, 101-124, doi:10.1256/qj.04.145. 
Beare, R. J., 2007: Boundary layer mechanisms in extratropical cyclones. Quart. J. Roy. Meteor. Soc., 133, 503-515, doi:10.1002/qj.30.

—, and M. J. P. Cullen, 2012: Balanced models of boundary-layer convergence. Quart. J. Roy. Meteor. Soc., 138, 1452-1464, doi:10.1002/qj.1877.

Blackadar, A. K., 1976: Modeling the nocturnal boundary layer. Preprints, Third Symp. on Atmospheric Turbulence, Diffusion and Air Quality, Amer. Meteor. Soc., Raleigh, NC, 46-69.

Bracewell, R. N., 2000: The Fourier Transform and Its Applications. McGraw-Hill, 616 pp.

Brachet, S., F. Codron, Y. Feliks, M. Ghil, H. Le Treut, and E. Simonnet, 2012: Atmospheric circulations induced by a midlatitude SST front: A GCM study. J. Climate, 25, 18471853.

Brayshaw, D. J., B. Hoskins, and M. Blackburn, 2008: The stormtrack response to idealized SST perturbations in an aquaplanet GCM. J. Atmos. Sci., 65, 2842-2860.

,$- \ldots$, and — 2011: The basic ingredients of the North Atlantic storm track. Part II: Sea surface temperatures. J. Atmos. Sci., 68, 1784-1805.

Bryan, F. O., R. Tomas, J. M. Dennis, D. B. Chelton, N. G. Loeb, and J. L. McClean, 2010: Frontal scale air-sea interaction in highresolution coupled climate models. J. Climate, 23, 6277-6291.

Charney, J. G., and A. Eliassen, 1949: A numerical method for predicting the perturbations of the middle latitude westerlies Tellus, 1, 38-54.

Chelton, D. B., and S.-P. Xie, 2010: Coupled ocean-atmosphere interaction at oceanic mesoscales. Oceanography, 23 (4), 52-69, doi:10.5670/oceanog.2010.05.

_ - and Coauthors, 2001: Observations of coupling between surface wind stress and sea surface temperature in the eastern tropical Pacific. J. Climate, 14, 1479-1498.

—, M. G. Schlax, M. H. Freilich, and R. F. Milliff, 2004: Satellite measurements reveal persistent small-scale features in ocean winds. Science, 303, 978-983, doi:10.1126/science.1091901.

,-- , and R. M. Samelson, 2007: Summertime coupling between sea surface temperature and wind stress in the California Current System. J. Phys. Oceanogr., 37, 495-517.

Czaja, A., and N. Blunt, 2011: A new mechanism for oceanatmosphere coupling in midlatitudes. Quart. J. Roy. Meteor. Soc., 137, 1095-1101, doi:10.1002/qj.814.

Durran, D. R., 1990: Mountain waves and downslope winds. Atmospheric Processes over Complex Terrain, Meteor. Monogr. No. 45, Amer. Meteor. Soc., 59-81.

Feliks, Y., M. Ghil, and E. Simonnet, 2004: Low-frequency variability in the midlatitude atmosphere induced by an oceanic thermal front. J. Atmos. Sci., 61, 961-981.

,-- , and,- 2007 : Low-frequency variability in the midlatitude baroclinic atmosphere induced by an oceanic thermal front. J. Atmos. Sci., 64, 97-116.

_ E. Tziperman, and B. Farrell, 2010: Nonnormal frontal dynamics. J. Atmos. Sci., 67, 1218-1231.

_, M. Ghil, and A. W. Robertson, 2011: The atmospheric circulation over the North Atlantic as induced by the SST field. J. Climate, 24, 522-542.

Frankignoul, C., N. Sennéchael, Y.-O. Kwon, and M. A. Alexander, 2011: Influence of the meridional shifts of the Kuroshio and the Oyashio Extensions on the atmospheric circulation. J. Climate, 24, 762-777.

Garratt, J. R., 1990: The internal boundary layer-A review. Bound.-Layer Meteor., 50, 171-203.

Gill, A. E., 1982: Atmosphere-Ocean Dynamics. Academic Press, $662 \mathrm{pp}$.
Hashizume, H., S.-P. Xie, M. Fujiwara, M. Shiotani, T. Watanabe, Y. Tanimoto, W. T. Liu, and K. Takeuchi, 2002: Direct observations of atmospheric boundary layer response to SST variations associated with tropical instability waves over the eastern equatorial Pacific. J. Climate, 15, 3379-3393.

Hayes, S. P., M. J. McPhaden, and J. M. Wallace, 1989: The influence of sea-surface temperature on surface wind in the eastern equatorial Pacific: Weekly to monthly variability. J. Climate, 2, $1500-1506$.

Holton, J. R., 2004: An Introduction to Dynamic Meteorology. 4th ed. Elsevier Academic, $535 \mathrm{pp}$.

Joyce, T. M., Y.-O. Kwon, and L. Yu, 2009: On the relationship between synoptic wintertime atmospheric variability and path shifts of the Gulf Stream and the Kuroshio Extension. J. Climate, 22, 3177-3192.

Kim, Y.-J., S. D. Eckermann, and H.-Y. Chun, 2003: An overview of the past, present and future of gravity-wave drag parameterization for numerical climate and weather prediction models. Atmos.-Ocean, 41, 65-98.

Klemp, J. B., and D. K. Lilly, 1978: Numerical simulation of hydrostatic mountain waves. J. Atmos. Sci., 35, 78-107.

, and R. B. Wilhelmson, 1978: The simulation of threedimensional convective storm dynamics. J. Atmos. Sci., 35, 1070-1096.

, J. Dudhia, and A. D. Hassiotis, 2008: An upper gravity-wave absorbing layer for NWP applications. Mon. Wea. Rev., 136, 3987-4004.

Kuwano-Yoshida, A., S. Minobe, and S.-P. Xie, 2010: Precipitation response to the Gulf Stream in an atmospheric GCM. J. Climate, 23, 3676-3698.

Lien, R.-C., and P. Müller, 1992: Normal-mode decomposition of small-scale oceanic motions. J. Phys. Oceanogr., 22, 1583-1595.

Lindzen, R. S., and S. Nigam, 1987: On the role of sea surface temperature gradients in forcing low-level winds and convergence in the tropics. J. Atmos. Sci., 44, 2418-2436.

Mahrt, L., 1975: The influence of momentum advections on a wellmixed layer. Quart. J. Roy. Meteor. Soc., 101,1-11, doi:10.1002/ qj. 49710142702 .

_ pumping on synoptic-scale flow. J. Atmos. Sci., 33, 1505-1520.

Mellor, G. L., and T. Yamada, 1982: Development of a turbulence closure model for geophysical fluid problems. Rev. Geophys. Space Phys., 20, 851-875.

Minobe, S., A. Kuwano-Yoshida, N. Komori, S.-P. Xie, and R. J. Small, 2008: Influence of the Gulf Stream on the troposphere. Nature, 452, 206-209, doi:10.1038/nature06690.

_- M. Miyashita, A. Kuwano-Yoshida, H. Tokinaga, and S.-P. Xie, 2010: Atmospheric response to the Gulf Stream: Seasonal variations. J. Climate, 23, 3699-3719.

Nakamura, H., T. Sampe, A. Goto, W. Ohfuchi, and S.-P. Xie, 2008: On the importance of midlatitude oceanic frontal zones for the mean state and dominant variability in the tropospheric circulation. Geophys. Res. Lett., 35, L15709, doi:10.1029/ 2008GL034010.

Nakanishi, M., and H. Niino, 2006: An improved Mellor-Yamada level-3 model: Its numerical stability and application to a regional prediction of advection fog. Bound.-Layer Meteor., 119, 397-407, doi:10.1007/s10546-005-9030-8.

Nonaka, M., H. Nakamura, B. Taguchi, N. Komori, A. KuwanoYoshida, and K. Takaya, 2009: Air-sea heat exchanges characteristic of a prominent midlatitude oceanic front in the South Indian Ocean as simulated in a high-resolution coupled GCM. J. Climate, 22, 6515-6535. 
O'Neill, L. W., D. B. Chelton, and S. K. Esbensen, 2003: Observations of SST-induced perturbations of the wind stress field over the Southern Ocean on seasonal timescales. J. Climate, 16, 2340-2354.

,$- \ldots$, and — 2005: High-resolution satellite measurements of the atmospheric boundary layer response to SST variations along the Agulhas Return Current. J. Climate, 18, 2706-2723.

,-- , and,$- 2010 \mathrm{a}$ : The effects of SST-induced surface wind speed and direction gradients on midlatitude surface vorticity and divergence. J. Climate, 23, 255-281.

—, S. K. Esbensen, N. Thum, R. M. Samelson, and D. B. Chelton, 2010b: Dynamical analysis of the boundary layer and surface wind responses to mesoscale SST perturbations. J. Climate, 23, 559-581.

— D. B. Chelton, and S. K. Esbensen, 2012: Covariability of surface wind and stress responses to sea surface temperature fronts. J. Climate, 25, 5916-5942.

Qiu, B., N. Schneider, and S. Chen, 2007: Coupled decadal variability in the North Pacific: An observationally constrained idealized model. J. Phys. Oceanogr., 20, 3602-3620.

Samelson, R. M., E. D. Skyllingstad, D. B. Chelton, S. K. Esbensen, L. W. O'Neill, and N. Thum, 2006: On the coupling of wind stress and sea surface temperature. J. Climate, 19, 1557-1566.

Sampe, T., H. Nakamura, A. Goto, and W. Ohfuchi, 2010: Significance of a midlatitude SST frontal zone in the formation of a storm track and an eddy-driven westerly jet. J. Climate, 23, 1793-1814.

Sasaki, Y., S. Minobe, T. Asai, and M. Inatsu, 2012: Influence of the Kuroshio in the East China Sea on the early summer baiu rain. J. Climate, 25, 6627-6645.

Shimada, T., and S. Minobe, 2011: Global analysis of the pressure adjustment mechanism over sea surface temperature fronts using AIRS/Aqua data. Geophys. Res. Lett., 38, L06704, doi:10.1029/2010GL046625.

Skamarock, W. C., and Coauthors, 2008: A description of the Advanced Research WRF version 3. NCAR Tech. Note NCAR/TN-475+STR, 113 pp.

Skyllingstad, E. D., D. Vickers, L. Mahrt, and R. Samelson, 2007: Effects of mesoscale sea-surface temperature fronts on the marine atmospheric boundary layer. Bound.-Layer Meteor., 123, 219-237, doi:10.1007/s10546-006-9127-8.

Small, R. J., S.-P. Xie, and Y. Wang, 2003: Numerical simulation of atmospheric response to Pacific tropical instability waves. J. Climate, 16, 3723-3741.

,,,--- S. K. Esbensen, and D. Vickers, 2005: Numerical simulation of boundary layer structure and cross-equatorial flow in the eastern Pacific. J. Atmos. Sci., 62, 1812-1830.

— , and Coauthors, 2008: Air-sea interaction over ocean fronts and eddies. Dyn. Atmos. Oceans, 45, 274-319, doi:10.1016/ j.dynatmoce.2008.01.001.

Song, Q., P. Cornillon, and T. Hara, 2006: Surface wind response to oceanic fronts. J. Geophys. Res., 111, C12006, doi:10.1029/ 2006JC003680.
—, D. B. Chelton, S. K. Esebensen, and L. W. O’Neill, 2008: Observations and modeling of SST influence on surface winds and the troposphere. Proc. Fifth Annual CoRP Science Symp., Corvallis, OR, Oregon State University. [Available online at http://cioss.coas.oregonstate.edu/CIOSS/workshops/CoRP symposium_08/Presentations/19_Song.pdf.]

,-- , S. K. Esbensen, N. Thum, and L. W. O'Neill, 2009: Coupling between sea surface temperature and low-level winds in mesoscale numerical models. J. Climate, 22, 146164.

Spall, M. A., 2007: Midlatitude wind stress-sea surface temperature coupling in the vicinity of oceanic fronts. J. Climate, 20, 3785-3801.

Svensson, G., and A. A. M. Holtslag, 2009: Analysis of model results for the turning of the wind and related momentum fluxes in the stable boundary layer. Bound.-Layer Meteor., 132, 261277, doi:10.1007/s10546-009-9395-1.

Taguchi, B., H. Nakamura, M. Nonaka, and S.-P. Xie, 2009: Influences of the Kuroshio/Oyashio Extensions on air-sea heat exchanges and storm-track activity as revealed in regional atmospheric model simulations for the 2003/04 cold season. J. Climate, 22, 6536-6560.

Takatama, K., S. Minobe, M. Inatsu, and R. J. Small, 2012: Diagnostics for near-surface wind convergence/divergence response to the Gulf Stream in a regional atmospheric model. Atmos. Sci. Lett., 13, 16-21, doi:10.1002/asl.355.

Tanimoto, Y., T. Kanenari, H. Tokinaga, and S.-P. Xie, 2011: Sea level pressure minimum along the Kuroshio and its extension. J. Climate, 24, 4419-4434.

Tokinaga, H., Y. Tanimoto, S.-P. Xie, T. Sampe, H. Tomita, and H. Ichikawa, 2009: Ocean frontal effects on the vertical development of clouds over the western North Pacific: In situ and satellite observations. J. Climate, 22, 4241-4260.

Wai, M. M., and S. A. Stage, 1989: Dynamical analyses of marine atmospheric boundary layer structure near the Gulf Stream oceanic front. Quart. J. Roy. Meteor. Soc., 115, 29-44.

Wallace, J. M., T. P. Mitchell, and C. Deser, 1989: The influence of sea-surface temperature on surface wind in the eastern equatorial Pacific: Seasonal and interannual variability. J. Climate, 2, 1492-1499.

Xie, S.-P., 2004: Satellite observations of cool ocean-atmosphere interaction. Bull. Amer. Meteor. Soc., 85, 195-208.

Xu, H., H. Tokinaga, and S.-P. Xie, 2010: Atmospheric effects of the Kuroshio large meander during 2004-05. J. Climate, 23, 4704-4715.

_ M. Xu, S.-P. Xie, and Y. Wang, 2011: Deep atmospheric response to the spring Kuroshio Current over the East China Sea. J. Climate, 24, 4959-4972.

Zhang, D., and R. A. Anthes, 1982: A high-resolution model of the planetary boundary layer-Sensitivity tests and comparisons with SESAME-79 data. J. Appl. Meteor., 21, 1594 1609. 